\title{
De la alquería de Benifassà a las granjas cistercienses de Ballestar y Cel Albar (1195-1279). (La Pobla de Benifassà, Castellón, España)
}

\author{
Manel Pica Torné \\ Universitat Autònoma de Barcelona \\ Manel.pica@gmail.com
}

\begin{abstract}
Resumen. El territorio de Benifassà se conquistó en 1233, cuando Blasco de Alagón tomó Morella. En ese momento empezó un complejo repartimiento fruto de las diferentes donaciones que los monarcas hicieron durante los ochenta años que Benifassà fue frontera entre al-Ándalus y la Corona de Aragón a distintos personajes. Esto obligó al recién fundado monasterio cisterciense de Santa María de Benifassà, filial de Poblet, a implantar en parte de su territorio granjas cistercienses, unidades de producción que siempre se asientan en territorios explotados anteriormente. En este caso se implantaron dos de éstas en el término de la alquería de Benifassà, una encima de la misma y la otra sobre su albar, un rahal no habitado con clara inclinación al secano.
\end{abstract}

Palabras clave: Benifassà, albar, alquería, granja cisterciense, hisn.

\begin{abstract}
The territory of Benifassà was conquered in 1233, at the same time that Blasco de Alagón conquered Morella. Then, it started a complex process of distribution of the territory in which monarchs did donations to different lords. During the eighty years in which the distribution was carried out, Benifassà was the frontier between al-Andalus and the Aragon Crown. That geographical situation forced the monastery of Santa María de Benifassà, a recent foundation as a filial of the cistercian monastery de Poblet, to introduce cistercian farms, which are characterized for be created in zones with a previous cultivation. Two of these farms were created inside the boundary of Benifassà's alquería, one over the ancient alquería strictly speaking and the other over its albar, an uninhabited rabal with clear tendency to be a rainfed land.
\end{abstract}

Keywords: Benifassà, albar, alquería, cistercian farm, bisn.

\section{Introducción}

A lo largo de las siguientes páginas presentaremos los primeros resultados de un proyecto de estudio más extenso centrado en los cambios producidos, con posterioridad a la conquista cristiana sobre al-Ándalus, en la Tenencia de Benifassà, del mismo modo que reflexionaremos sobre las posibilidades de estudio que nos ofrece este territorio, situado en la zona más septentrional del País Valenciano, justo en la confluencia con las comunidades de Aragón y Cataluña, en la cordillera de els Ports. Situación que le confiere una orografía montañosa, con estrechos y escarpados valles, dónde nacen múltiples fuentes que nutren la cabecera de dos ríos: el Sènia y el Escalona.

Esta sub-comarca del Bajo Maestrazgo castellonense está formada por siete pueblos: Castell de Cabres, Boixar, Coratxà, Fredes, Bel, Ballestar y La Pobla de Benifassà. Todos ellos tienen en común la pertenencia al mismo señorío durante la Edad Media y Moderna, el monasterio cisterciense de Santa Maria de Benifassà, filial de Poblet, fundado por el rey Jaime I en el año $1233^{1}$, siendo así el primer monasterio del que, posteriormente, sería el Reino de Valencia.

\footnotetext{
${ }^{1}$ Archivo de la Catedral de Tortosa (ACT), Cajón Benifassà, no 4.
} 


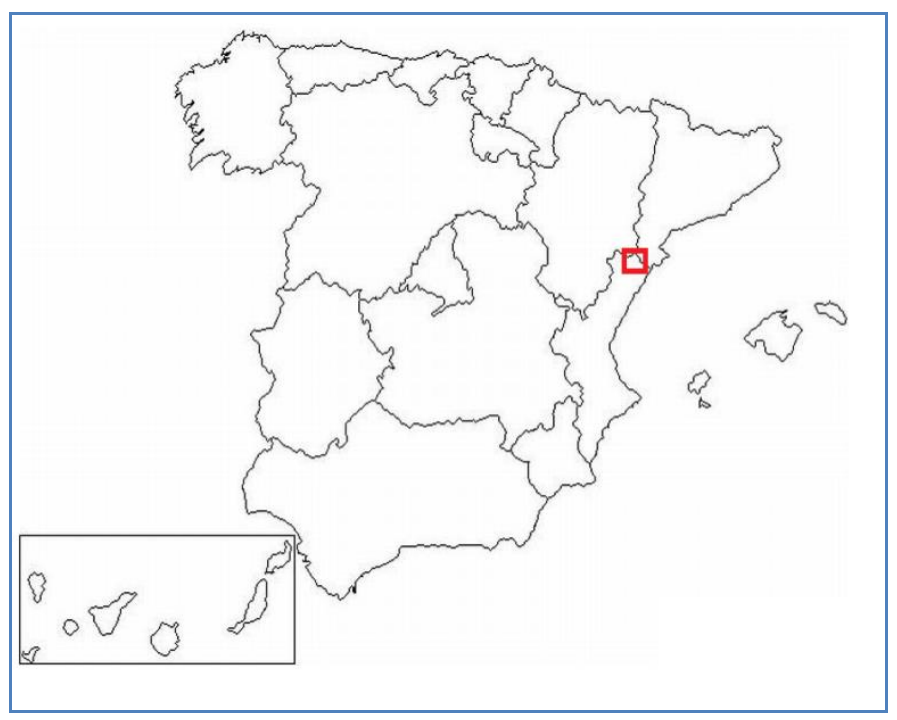

Fig.1. Localización de La Tenencia de Benifassà en la Península Ibérica

Las fuentes árabes no nos dicen nada de este territorio que, durante más de ochenta años, fue frontera entre al-Ándalus y la Corona de Aragón, esta última con clara voluntad expansiva (Guinot, 1995). Fruto de esta localización y de los años de frontera los distintos monarcas catalanes dieron el mismo territorio en distintas ocasiones a diferentes personalidades, documentos a partir de los que podemos establecer la organización castral andalusí previa a la conquista. Así, En primer lugar, el año 1195, el rey Alfonso el Casto dio el castrum y término Benifassà al prior de la Sede de Tortosa (Virgili, 2001, P.525). En segundo lugar, Pedro el Católico entregó, el año 1208 el mismo emplazamiento a Guillem de Cervera (Font i Rius, 1969, p. 227), quien en 1229 lo cedería a Poblet ${ }^{2}$, siendo ésta la base para la futura fundación del monasterio, y el 1210, el mismo monarca concedió el castrum de Cabres y su término a Artal de Alagón ${ }^{3}$, el que, dos años más tarde, lo cedería a su hijo Blasco ${ }^{4}$. Finalmente, ya en el reinado de Jaime el Conquistador, Blasco de Alagón conquistó Morella (Arroyo, 1973). Entonces, a raíz del privilegio entregado al noble por el rey en $1226^{5}$, con el que el aragonés podía proclamarse señor de cualquier plaza conquistada en tierra de moros, se proclamó Señor de Morella y su territorio, área que englobaba, entre otros, los términos de los husun de Benifassà y Castell de Cabres.

Esta proclamación abrió una disputa entre Blasco y el rey Jaime I, el que para intentar limitar el poder del nuevo Señor de Morella y forzar la entrega de la plaza a la corona, mandó al monasterio de Poblet fundar una filial suya en el territorio de Benifassà, del mismo modo que le amplió el territorio, entregándoles el castrum y término de Cabres, a excepción de Herbesset que seguiría vinculado a Morella ${ }^{6}$. Así, gracias a las disputas entre el noble y el monarca, el monasterio de Benifassà adquirió el 1233 los términos de dos busun: Castell de Cabres, con los núcleos de Boixar, Coratxà y Castell de Cabres, y de Benifassà, con Fredes, Bel y la alquería de Benifassà, ambos dependientes de Morella en la anterior etapa andalusí.

\footnotetext{
2 Archivo Histórico Nacional (AHN), Clero, secular-regular, carpeta 418, n²

${ }^{3} \mathrm{AHN}$, códices y cartularios, 1126-B

${ }_{4}$ Archivo de la Corona de Aragón, ACA, Condado de Sástrago, pergaminos, no 4

${ }^{5}$ Entregado al noble aragonés cuando se puso de lado del rey en la revuelta de Pedro Ahonés. Archivo Municipal de Valéncia. Pergamino original.

${ }^{6}$ Ver figura 2.
} 
No se puede determinar con exactitud cuándo Blasco de Alagón cedió la plaza al monarca, todo parece indicar que fue a finales de 1233 (Belenguer, 2007, págs. 109-10), momento en que le sería devuelta como señor vitalicio ${ }^{7}$. Esto situaría la fundación del monasterio de Benifassà por el rey Jaime, datada el 22 de noviembre de $1233^{8}$, como la primera acción del monarca en un territorio ya en su posesión o, también, como la última forma de forzar y limitar el poder de Blasco en el territorio morellano, aun con todo, fue a razón de estas desavenencias que el termino de Benifassà uniera dos términos bien diferenciados hasta este momento.

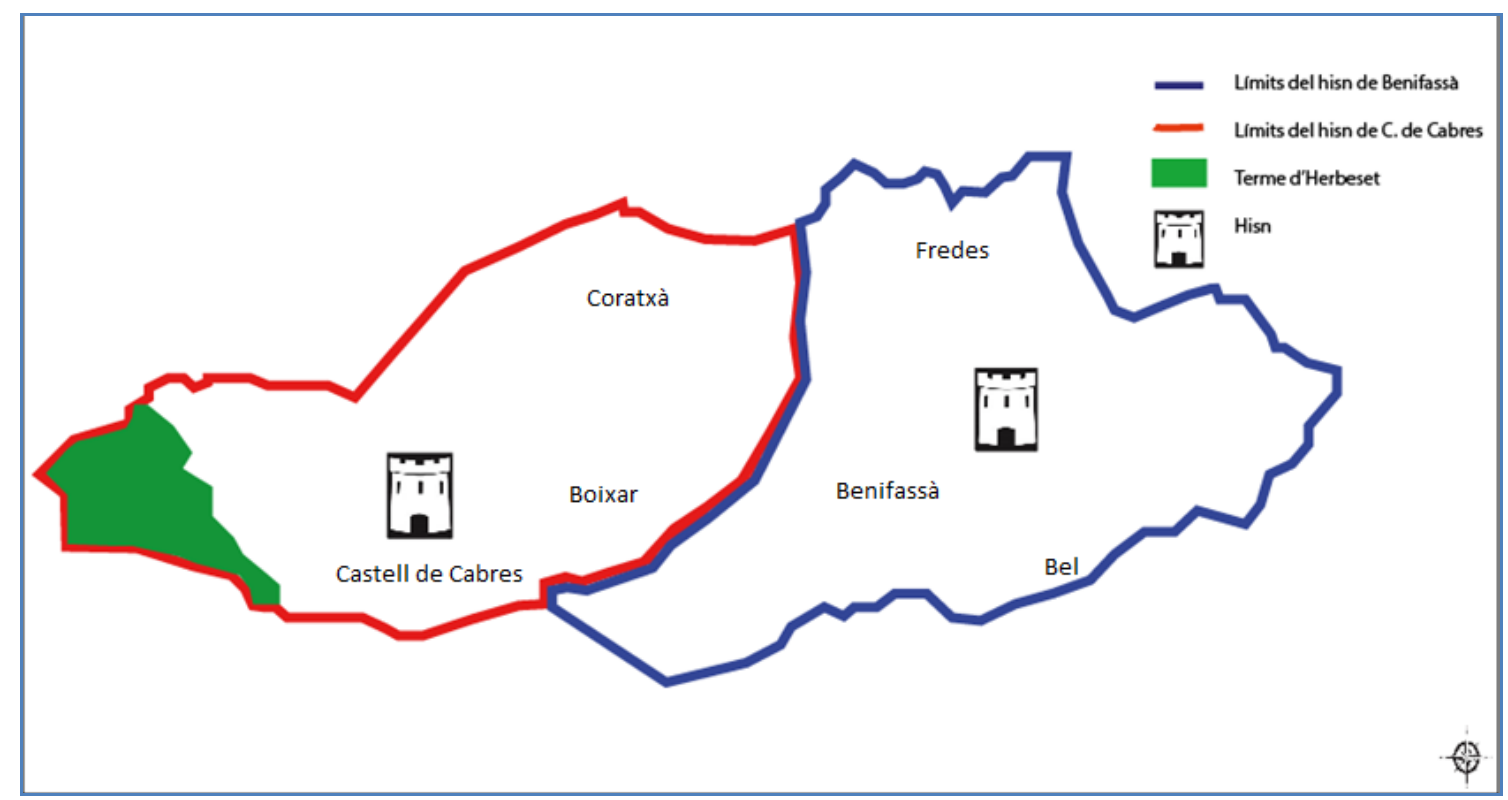

Fig. 2. Términos de los busun de Castell de Cabres y Benifassà, unidos por el rey en 1233

La fundación del monasterio no quedó libre de disputas, y dado que todos los agentes que habían recibido el territorio -Catedral de Tortosa, Poblet y Blasco de Alagón- querían ejercer sus derechos sobre el mismo, se abrió un periodo de acuerdos y concordias entre ellos para poder definir el reparto de derechos. Por lo que respecta a Blasco de Alagón, se encargó de poblar y gestionar, durante su vida, el término del hisn de Castell de Cabres", haciendo valer la donación de Pedro I a su padre ${ }^{10}$. Además, el año $1234^{11}$ Blasco donó el término de Coratxà a Santa María de Escarp, donación que un año más tarde repetiría el rey Jaime ${ }^{12}$, añadiendo un cuarto agente conquistador en el mismo término. No fue hasta la muerte del aragonés que el monasterio controló el término de Castell de Cabres ${ }^{13}$, y no

\footnotetext{
${ }^{7}$ ACA, Cancelleria Real. Pergaminos de Jaime I, $n^{\circ} 643$.

8 ACT, Cajón Benifassà, $n^{\circ} 4$.

${ }^{9}$ Blasco de Alagón entrega carta de población a Castell de Cabres (Guinot, 1991, p. 4) y Coratxà (Guinot, 1991, p. 18), así como la Penya de Bel (Guinot, 1991, p. 11), la Mola Escabrosa (Guinot, 1991, p. 26) y Vilanova (Guinot, 1991, p. 19), todos en el término de Castell de Cabres, y Boixar y Fredes, como un único municipio en término de Boixar (Guinot, 1991, p. 16), y la Penya de l'Aranyonal (Guinot, 1991, p. 20), en el territorio de Coratxà. A més, en el seu testamento, datado el 1239 deja "en poder e en mano de don Pedro Sessé, Castiel de Cabras e El Buxar e Corachan, assí como yo las poblé en mi término, con la mitat de las décimas de las ecclesias, e con todas las exidas d'aquellos logares" (ACA, Condado de Sástrago, pergaminos, $\mathrm{n}^{\circ} 1$ ). Ésta mitad del diezmo fue concedida por Ponç, Obispo de Tortosa, el 2 de mayo de 1235 (ACT, Cartulari 8, f.103 n 57).

${ }^{10} \mathrm{AHN}$, códices y cartularios, 1126-B

11 AHN, códices y cartularios, 1126-B, f. 113 r-113v.

12 AHN, clero, regular-secular, carp. $419, \mathrm{n}^{\circ} 11$

${ }^{13}$ Habiendo de comprar ciertos derechos a personalidades que los tenían, por ejemplo Elió en la Penya de Bel. AHN. Còdex i cartularis, 1126-B. f. 111r-111v.
} 
todo, ya que Coratxà seguiría en posesión del monasterio leridano cisterciense de Santa María de Escarp hasta su compra en 1283 por parte de Benifassà ${ }^{14}$. Así, durante los primeros años el monasterio perdió el control sobre la mitad de su término a la vez que la Catedral de Tortosa consiguió, mediante concordias, obtener derechos muy favorables en el territorio de Benifassà ${ }^{15}$.

Ante esta difícil situación institucional, el monasterio empezó por un lado a formar un importante dominio exterior que escapara de la problemática, hecho habitual en la fundación de cenobios $^{16}$, y por el otro, puso en marcha la utilización de formas de producción en el interior de su término que redujeran los pagos, en especial a la Catedral de Tortosa. Así, el monasterio decidió no poblar su territorio y lo organizó a partir de granjas cistercienses, que al ser territorios explotados directamente por los monjes, no debían pagar diezmo, y al no formar poblaciones, tampoco la primicia (Bolós, 2005). Además, únicamente ellos podían decidir si construían molinos o hornos, infraestructuras en los que la Catedral tenía derechos. Esta situación se mantendría hasta la década de 1260, cuando la catedral y el monasterio regularon un reparto de derechos más favorable al cenobio, decidiendo éste finalmente poblar su valle ${ }^{17}$. Aun con todo, la concesión de cartas de población no quedó al margen de este proceso, ya que los abades las otorgan con la condición que no se construyan nuevos molinos, evitando así la pérdida de ingresos. Por tanto, no encontraremos en el término del antiguo hisn de Benifassà ningún molino construido en etapa feuda $1^{18}$, plasmación de las disputas señoriales en el territorio.

El concepto granja es difícil de definir y la ambigüedad con la que lo utilizan los monjes es de poca ayuda porque puede definir distintos emplazamientos y tipos de producción según el lugar ${ }^{19}$. De los cuatro núcleos de población que se generaron con la entrega de cartas puebla en el término del hisn de Benifassà, todos habían recibido el calificativo de granja. Aun con todo, sabemos que los actuales La Pobla, antigua granja de Cel Albar, y el Ballestar, cumplían las características de las granjas cistercienses, no siendo así en el caso de Fredes y Bel, es decir, los primeros, tienen oratorio, distan a menos de una jornada del monasterio y, aunque no se ha detectado la presencia de mayoral o grangiarius, sí que tienen una gestión directa del "cellerarius" del monasterio (Bolós, 2005). También sabemos que de las dos, el Ballestar, más próxima al monasterio sería la principal, de la que dependerían las otras. Sin embargo, la característica más importante de las granjas cistercienses es que siempre se asientan en territorios ya explotados anteriormente, evitando así nuevas roturaciones para obtener una producción más inmediata ${ }^{20}$ (Bond, 2003).

\footnotetext{
${ }^{14}$ La posesión de Coratxà abrió un pleito entre los dos monasterios, estudiado por Vicent Domènech (1984). Aunque, el mismo autor destaca las buenas relaciones de los dos cenobios cistercienses durante la disputa.

${ }^{15} \mathrm{La}$ mitad del diezmo y la totalidad de las primicias y los hornos y molinos de nueva construcción. AHN, Clero, regular-secular, Carpeta $\mathrm{n}^{\circ} 418, \mathrm{n}^{\circ} 11$.

16 Por ejemplo, los primeros cincuenta años de vida del monasterio de Santes Creus (Carreras, 1992), o las primeras décadas de Poblet (Altisent, 1974) o, ya en el Reino de Valencia el caso de Valldigna (Garcia-Oliver, 1998, págs. 32-45).

17 ACT, cajón Benifassà, no1.

${ }^{18}$ No será hasta la etapa napoleónica cuando se construirán algunos molinos en éste término. Así, la Catedral de Tortosa únicamente establece molinos en Boixar y Castell de Cabres. ACT, Benifassà, pergaminos no 20, 21 y 22

${ }^{19}$ Se ha constatado en el Valle de Codoç como poblet va adquiriendo diferentes tierras y después les aplica el calificativo de granja sólo para remarcar su unidad jurídica y de gestión (Batet, 2006, pág. 51)

${ }^{20}$ En este sentido, contamos con múltiples ejemplos de éste hecho, por ejemplo en la Península Iberica hay los ejemplos de San Tirso (Zamora), granja fundada en un territorio que explotaba salinas para el monasterio de Sobrado de los Monjes en La Coruña (Rodríguez, 2005) i la de Constantín, fundada por el mismo monasterio sobre una explotación de hierro (Pallares, M.C; Portela, E, 2000). Por otro lado, a nivel europeo
} 
A lo largo de las siguientes páginas nos centraremos en analizar sobre que espacios se asentaron las dos granjas que cumplen las características, es decir, Ballestar y Cel Albar, las que finalmente, con la decisión de poblar el valle del monasterio, resultaron villas ${ }^{21}$, con nuevos topónimos que no aparecían en las primeras donaciones, sino a partir del momento que desaparece el de alquería de Benifassà. Para llevar a cabo el estudio, partiremos de la aplicación metodológica de la arqueología hidráulica. Disciplina, nacida hace treinta años con las primeras propuestas de estudio hidráulico de las huertas medievales, formuladas por Miquel Barceló (Barceló, 1988), las cuales fueron rectificadas y ampliadas por el mismo (Barceló, 1999), y con la formulación metodológica de Helena Kirchner y Carme Navarro (1996). La aplicación sistemática de ésta metodología en el mundo andalusí ha generado un cuerpo empírico de más de 160 casos, estudiados entre las Islas Baleares, realizados, en gran proporción, por el equipo de M. Barceló (Kirchner, 1997) (M. Barceló, F. Retamero, 2005), el País Valenciano (Guinot, 2005) (Esquilache, 2011) y, en menor proporción, en las zonas de Lleida (Eritja, 2000) y Tortosa (Guinot, 2002) (Kirchner,H; Virgili, A; Antolín, F., 2014). Esta abundancia de estudios ha permitido definir las morfologías, las tipologías y los tamaños de las huertas (Kirchner, 2012), así como las opciones sociales que determinan su implantación (Retamero, 2006).

\section{El espacio agrario de El Ballestar}

Los espacios de huerta del municipio de El Ballestar se localizan en dos partidas. La primera de ellas está situada al norte del núcleo urbano, en el camino de la ermita de la Trinidad y sin toponimia que la identifique, la segunda, se encuentra emplazada en el suroeste del pueblo, en los márgenes del torrente dels Horts, tomando éste el mismo nombre que la partida. Cabe indicar que las dos partidas se encuentran en los pies del cerro en la cima del cual encontramos el pueblo, desde donde se pueden controlar los dos espacios ${ }^{22}$.

Ambas partidas presentan notables diferencias, tanto en morfología parcelaria, como en sistemas de riego. Por lo que a sistemas de riego se refiere, la documentación recogida con posterioridad a la granja no aporta ninguna mención a los mismos, aunque el cultivo mayoritario sea la huerta (45\%). Cabe indicar que el porcentaje de menciones a cultivo de vid $(33 \%)$ es indudablemente superior al que se registraría justo en el momento de la conquista, ya que los sucesivos abades promueven el cultivo de ésta por encima de otros ya en cronologías muy tempranas.

La partida del norte tiene una extensión de 8,2 hectáreas con posibilidad de irrigación, aunque en la actualidad, está mayoritariamente abandonada y muchos de los pozos secos. Presenta una morfología parcelaria con grandes recintos, regados por pozos de cenia, a excepción de una parcela de 0 '9 ha, regada por una balsa que recoge el sobrante de un aljibe que, en primera instancia, abastece un abrevadero, ya que la partida es cruzada por una cañada. Ésta descripción contiene diferentes aspectos que nos conducen a pensar en que se trata de una ampliación.

encontramos los ejemplos de Glénon (Francia), fundada sobre una villa carolíngia por el monasterio de Vauxsur-Poligny (Chauvin, 1983) o la granja de Roystone (Anglaterra), fundada sobre un espai agrícola d'ocupació romana (Hodges, 1991).

${ }^{21}$ Es un hecho habitual que las granjas cistercienses se conviertan en nuevas poblaciones (Virgili, 2005, pág. 90).

${ }^{22}$ Los libros de agricultura andalusíes establecen que, preferiblemente, las huertas tienen que ubicarse en zonas que se controlen desde los lugares de residencia (Trillo, 1999, pág. 135). 
En primer lugar, vemos como las parcelas presentan unos tamaños que sólo en algún caso llegan a superar la hectárea de superficie, no siendo ninguna de ellas inferior a media hectárea. Si partimos de la base que los espacios de riego andalusíes son de dimensiones pequeñas, siendo un porcentaje muy reducido los sistemas que presentan más de dos hectáreas (Sitjes, 2006, 284), podemos observar como toda esta partida responde a una ampliación moderna.

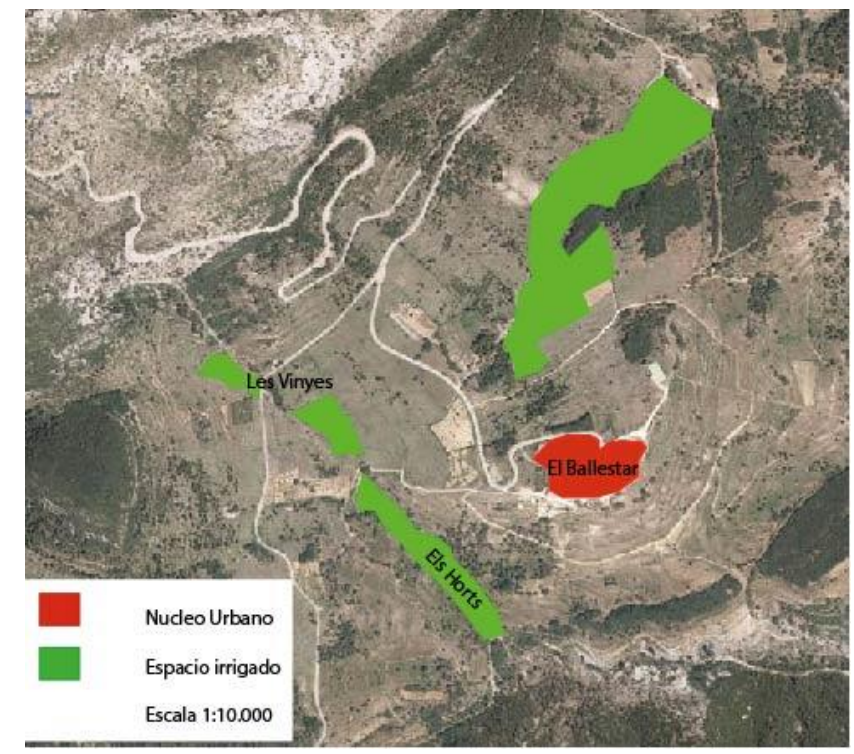

Fig. 3. Situación de los espacios irrigados en relación al municipio de El Ballestar.

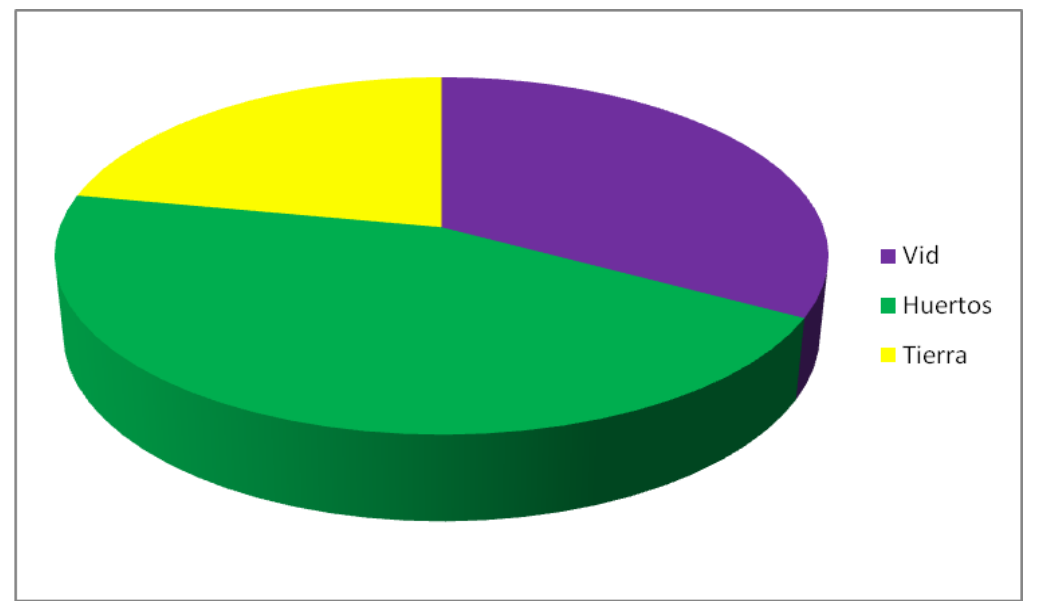

Fig.4. Menciones a cultivos en la documentación de El Ballestar

En segundo lugar, y de forma más hipotética, observamos la presencia de un aljibe que abastece un abrevadero, así como del paso de dos cañadas justo por los márgenes de la huerta. Se ha constatado que los caminos ganaderos andalusíes no coinciden con los espacios irrigados en continua producción (Trillo, 1999, pág. 136) ${ }^{23}$, alejando así el peligro de ser perjudicados por la acción animal. Por lo tanto, el paso de estas cañadas podría ser otro indicador de ampliación.

\footnotetext{
${ }^{23}$ Afirmación que en numerosos artículos se atribuye a una conferencia ofrecida por Watson en el Congreso realizado el año 1992, entre Granada y Valencia, en honor a Pierre Guichard. Las actas siguen sin ser publicadas y difícilmente se publiquen, por eso citamos a Carmen Trillo.
} 
Sin embargo, el paso de las cañadas utilizados en ésta investigación son extraídos de las ordinaciones del monasterio de Benifassà ${ }^{24}$, siendo ésta la primera legislación que se documenta en el territorio después de la conquista ${ }^{25}$. Podríamos pensar que las cañadas feudales no fueran coincidentes con las andalusíes, aunque encontramos diferentes indicios que nos conducen a pensar en el mantenimiento de las mismas.

En primer lugar, ya indicábamos que la legislación de los pasos ganaderos es la primera que se documenta en el territorio. Este elemento es poco concluyente por sí solo, pero si lo ponemos en relación con qué el monasterio de Poblet desde el año 1217 obtuvo el permiso del gobernador de Valencia para pastar sus rebaños en estas tierras (Dagorn, 1975), nos conduce a ver que los monjes ya tenían conocimiento de las cañadas andalusíes y eran utilizadas por ellos antes de la implantación del monasterio.

Además, en segundo lugar, las ordinaciones respecto a las penas impuestas a los pastores cuyos rebaños entraran en huertos ajenos causando daños no aparecen hasta tiempos muy posteriores, entendiendo así que ésta problemática no se produjo en los primeros años, sino fruto de las ampliaciones del espacio irrigado ${ }^{26}$.

Finalmente, los espacios determinados por nosotros como huertas andalusíes, a día de hoy presentan un alejamiento de estas infraestructuras ganaderas y nos conduce otra vez a pensar en el mantenimiento de las vías. Aún con todo, sólo el estudio completo de la Tenencia de Benifassà y de estas cañadas podrá ser concluyente en este sentido.

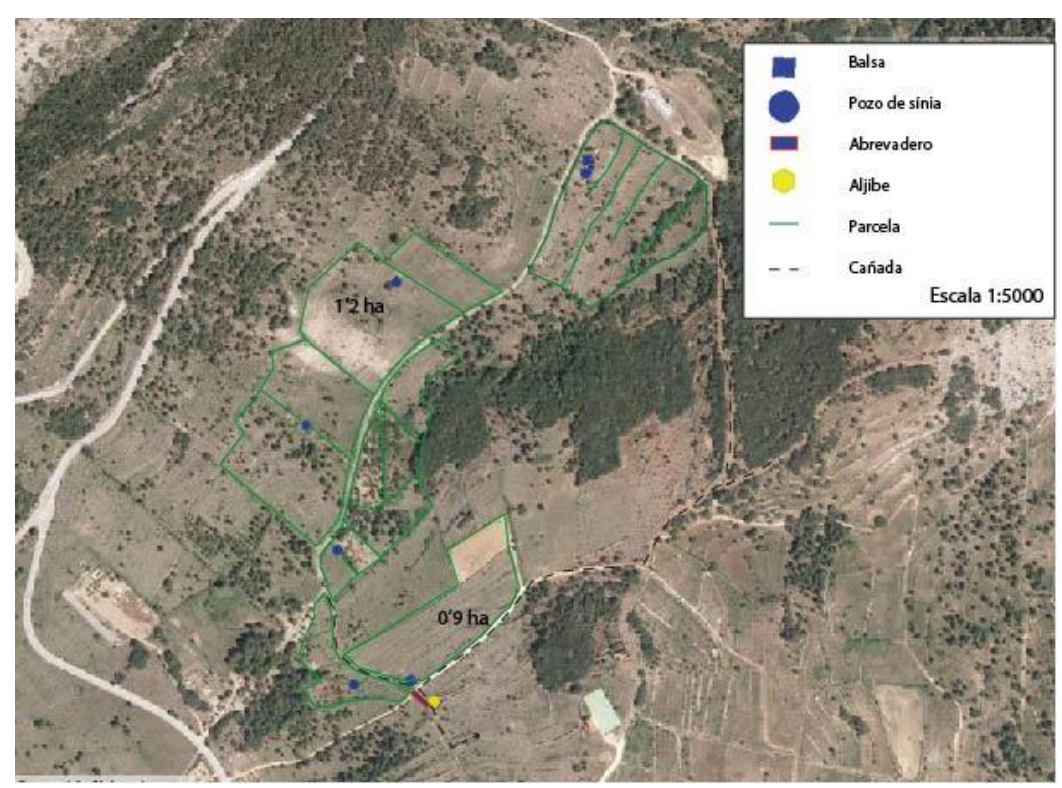

Fig.5. Espacio irrigado del norte de El Ballestar con sistemas de riego y cañadas.

\footnotetext{
${ }^{24}$ ACT, Índice del Archivo del monasterio de Benifassà. Las 25 últimas páginas del índice del archivo recogen las ordinaciones del monasterio.

${ }^{25}$ La copia llegada a nosotros es una traducción al castellano de la traducción catalana que se hizo del texto en latín, (ACT, Índice del Archivo de Benifassà).

${ }^{26}$ Las ordinaciones del monasterio de Benifassà no legislan contra éste hecho hasta el siglo XVI y en las del municipio del Boixar hay que esperar a las ordinaciones del siglo XIV y XV para encontrar la legislación (Mateu i Llopis, 1969).
} 


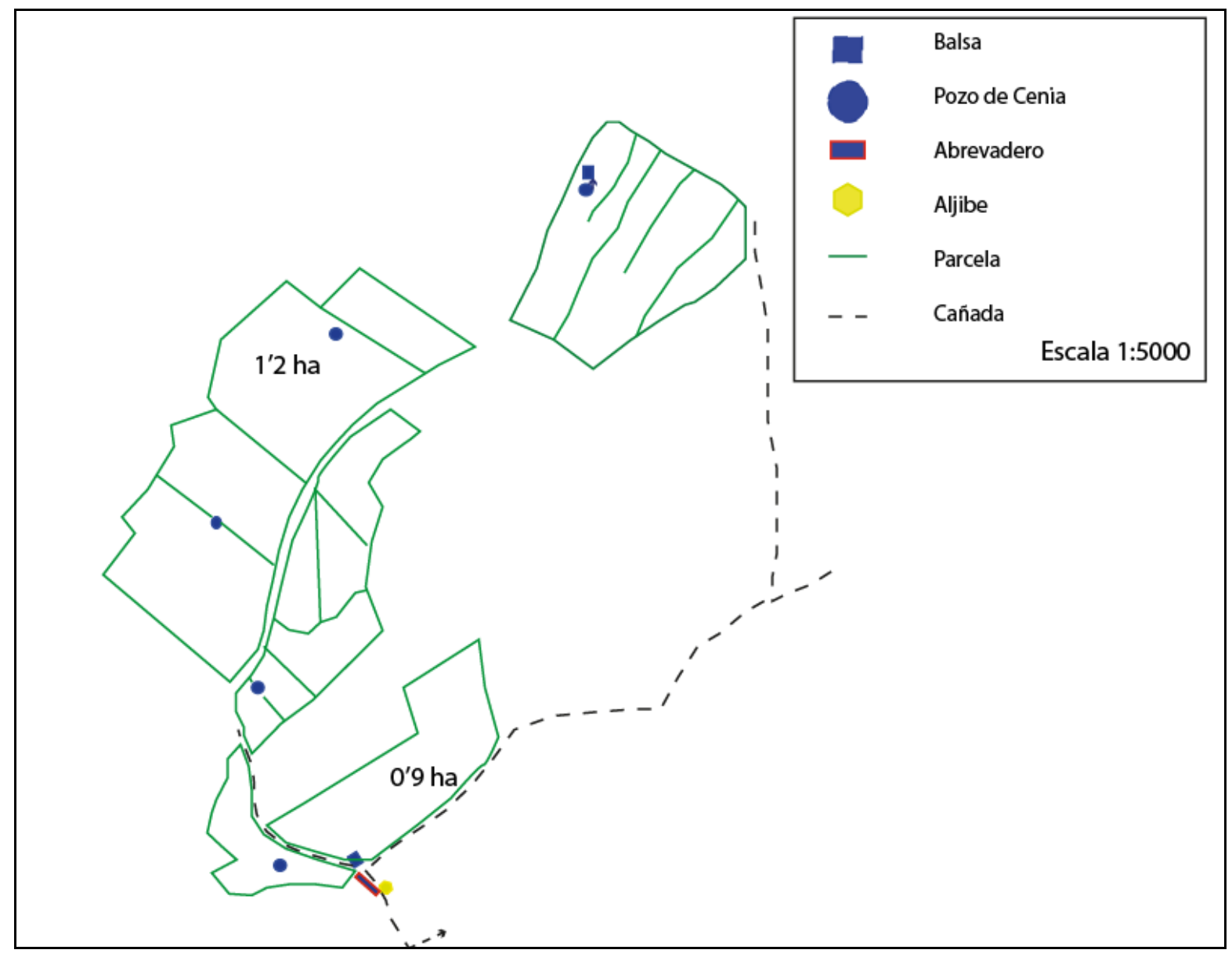

Fig. 6. Espacio irrigado del norte de El Ballestar con sistemas de riego y cañadas.

Muy diferente es la situación de la partida de los Horts, ya que los parcelarios de ésta se sitúan en los márgenes del torrente homónimo, canalizado con paredes de piedra seca. Las parcelas quedan delimitadas por el fondo de valle y adaptadas a los cambios de nivel del terreno confiriéndoles unas dimensiones reducidas. Ambos parcelarios se riegan por acequia, aunque con captaciones distintas.

En primer lugar, la captación se realiza mediante una fuente dónde, a escasos metros de su salida a la superficie, encontramos un azud que conduce el agua a los lavaderos, y en la salida de éstos encontramos tres desviaciones. La primera de ellas genera un canal de pocos metros que riega una única parcela, situada en el margen derecho del torrente. La segunda, origina una acequia que abastece una balsa con la que se riegan también tres parcelas en el mismo margen. Finalmente, la tercera conduce el cauce a una acequia que riega íntegramente el parcelario del margen izquierdo. Esta acequia tiene un recorrido de aproximadamente 350 metros, en los que abastece de agua todas las parcelas que comprende el área entre ella y el torrente. Es a medio recorrido donde encontramos una balsa que se nutre de ella, pero que no interfiere en el camino de la misma, entendiendo que es una balsa que únicamente regula el turno de riego. Cabe indicar que a la altura de la balsa la acequia tiene una desviación que riega dos parcelas, separadas del sistema y con una morfología completamente diferente. Esto nos conduce a pensar que estas últimas responden a una ampliación del sistema, de la misma manera que es plausible pensar en que de las tres desviaciones sólo la tercera acequia y principal respondiera a época andalusí, aunque en este caso sólo la obtención de dataciones absolutas podría determinarlo. 


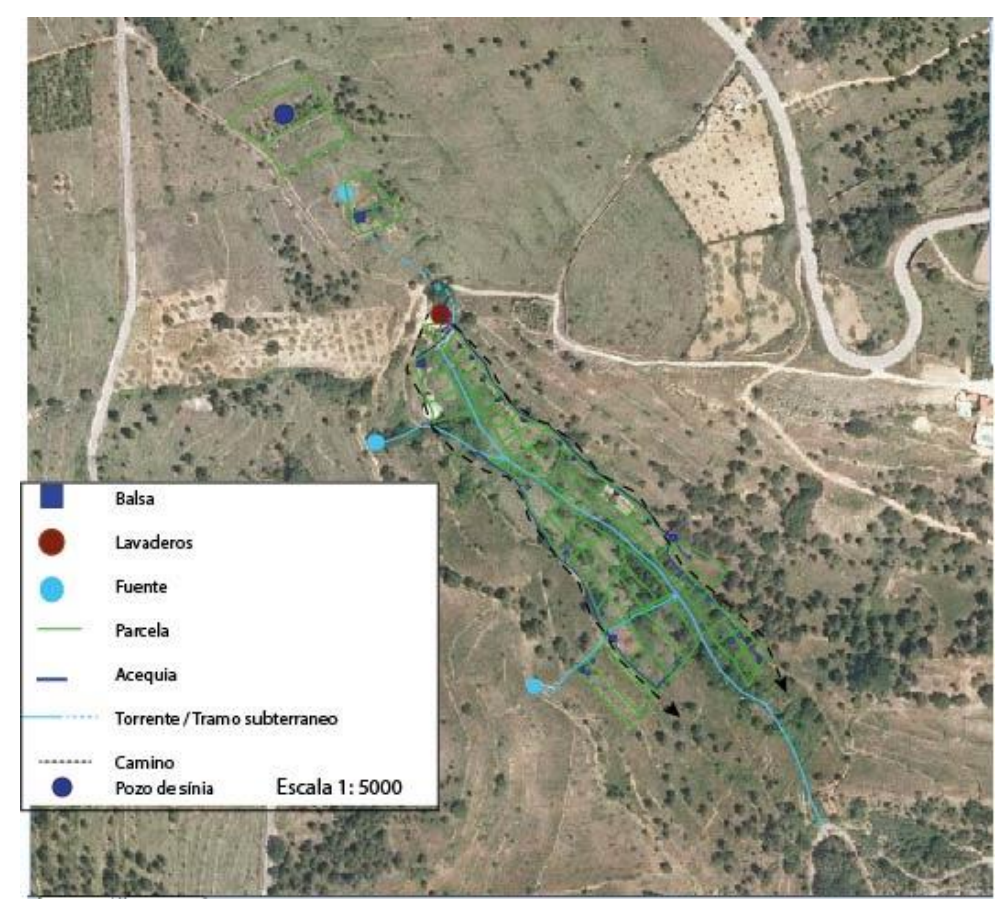

Fig. 7. Espacio irrigado de la partida dels Horts de El Ballestar con sistemas de riego

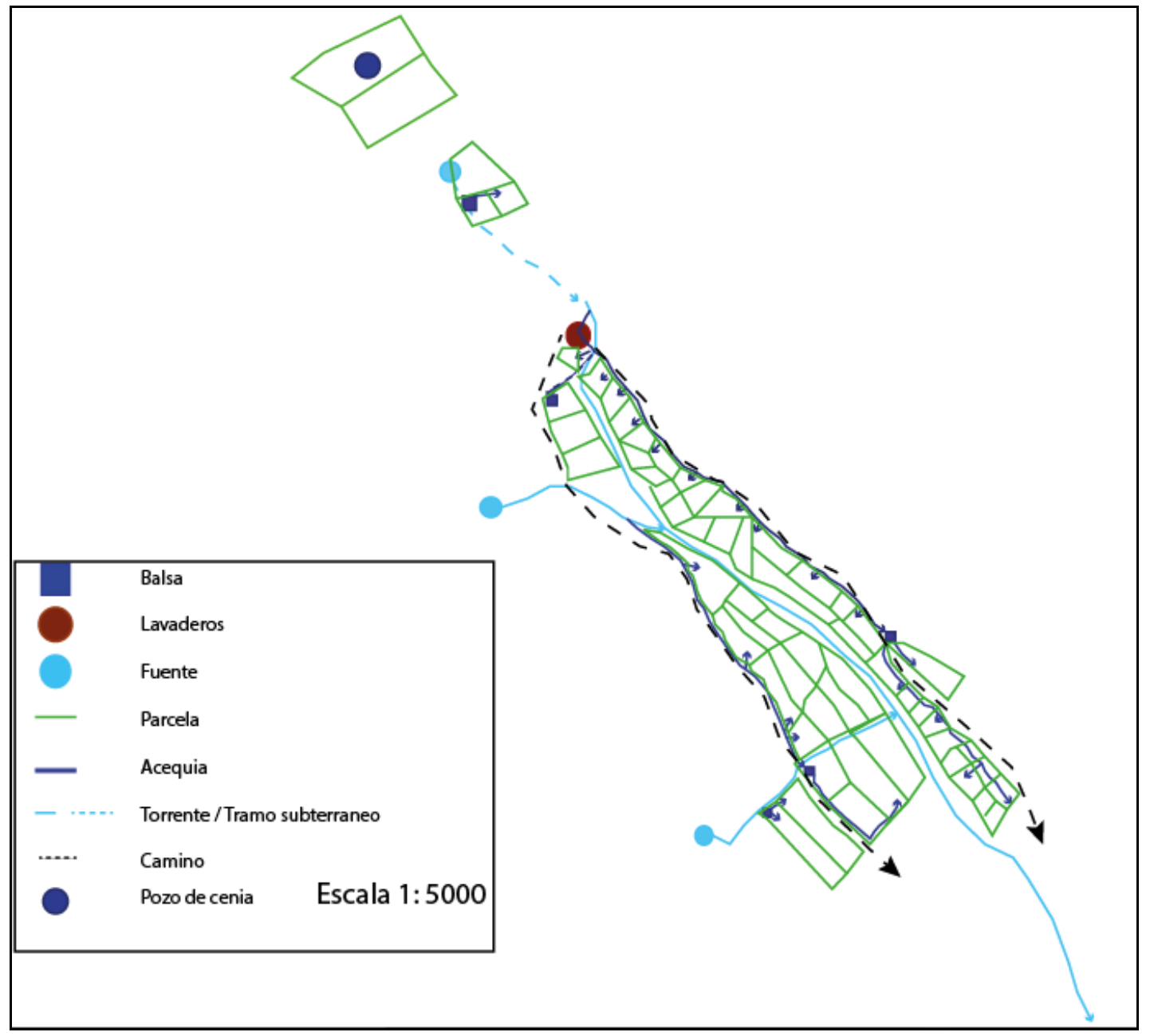

Fig. 8: Espacio irrigado de la partida dels Horts de El Ballestar con sistemas de riego 
En el margen derecho del torrente, la captación se produce a partir de un torrente que desemboca en el principal, en el que mediante un azud se abastece una acequia de 130 metros que riega las parcelas que tiene entre ella y el torrente. La canalización tiene situada al final del recorrido una balsa, emplazada en el centro de una parcela que se nutre de ella y alarga el sistema unos quince metros para regar un parcelario de morfología muy regular, distinta a la de los anteriores. Además, la balsa se localiza con posterioridad a un segundo torrente que desemboca en el de los Horts, cauce que sería la desembocadura primigenia de la acequia, siendo éste tramo final una ampliación. Las parcelas que quedan por encima del camino, también regulares y regadas por una balsa que se abastece de agua de éste segundo torrente, serían también resultado de una ampliación.

Así, podemos ver que si descartamos las parcelas consideradas ampliaciones nos resulta un parcelario de posible riego andalusí con una superficie inferior a una hectárea ( $\left.0^{\prime} 9 \mathrm{ha}\right)$, siendo estas las medidas más habituales dentro de los espacios irrigados andalusíes estudiados (Sitges, 2006). Aun con todo, no puede ser sólo la morfología y las dimensiones lo único que nos determine este espacio como la huerta primigenia.

La documentación más próxima a la conquista nos muestra que los huertos alienados en el Ballestar presentan muchas delimitaciones con el torrente ${ }^{27}$, pero también con dos caminos, el de los huertos " $a$ part de Ballestar 28 " y el que lleva "al cap dels Horts" 29 . Podemos determinar que son dos caminos diferentes porque encontramos parcelas que delimitan con ambos ${ }^{30}$, dejando el torrente en medio del parcelario. Éste tipo de parcelación, igual que los caminos, siguen vigentes hoy en día, ya que hay propietarios que mantienen parcelas contiguas pero separadas por el torrente, delimitando así con las dos vías. El hecho de no encontrar delimitaciones con las acequias en ninguno de los documentos no es de extrañar, ya que el sistema hidráulico transcurre por la parte interior del camino, así nunca limita con el huerto, desviando el agua por pequeñas canalizaciones cubiertas por la vía.

\section{Espacio agrario de La Pobla de Benifassà}

En el caso de la granja de Cel Albar, actual La Pobla de Benifassà, encontramos tres zonas irrigadas. En primer lugar, la partida dels Horts, al este del municipio, a poca distancia del Ballestar. En segundo lugar, los huertos situados en la misma ladera en la que se emplaza el núcleo urbano, conocida en la documentación como: "Davall la vila" encontramos unas parcelas irrigadas por la acequia de la Font Lluny, situadas en el margen derecho del lecho del río Sènia, aún seco en este tramo. La documentación recogida nos documenta la partida dels Horts y la de "Davall la vila". Por otro lado, las menciones a cultivos nos ofrecen una notable diferencia con las de Ballestar, ya que se reduce a la mitad el porcentaje de huertos $(22 \%)$ y aparecen los forrajes $(12 \%)$, cuestión sobre la que hablaremos más adelante.

\footnotetext{
27 AHN, clero, secular-regular, Carpeta 433, no 7, 8, 13. AHN, clero, secular-regular, Carpeta 439, $n^{\circ} 6$

28 AHN, clero, secular-regular, Carpeta 438, no 12

${ }^{29} \mathrm{AHN}$, clero, secular-regular, Carpeta $436, \mathrm{n}^{\circ} 3$

${ }^{30} \mathrm{AHN}$, clero, secular-regular, Carpeta 438, no 12

31 AHN, clero, secular-regular, Carpeta 440, no 13
} 


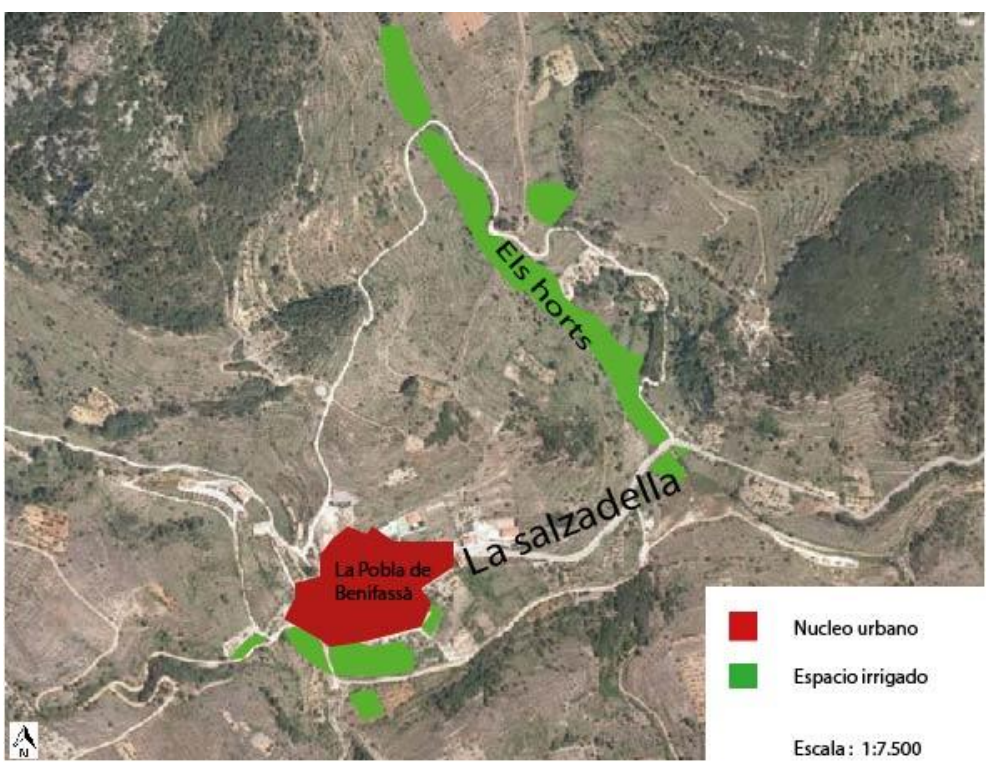

Fig. 9. Situación de los espacios irrigados en relación al municipio de El Ballestar.

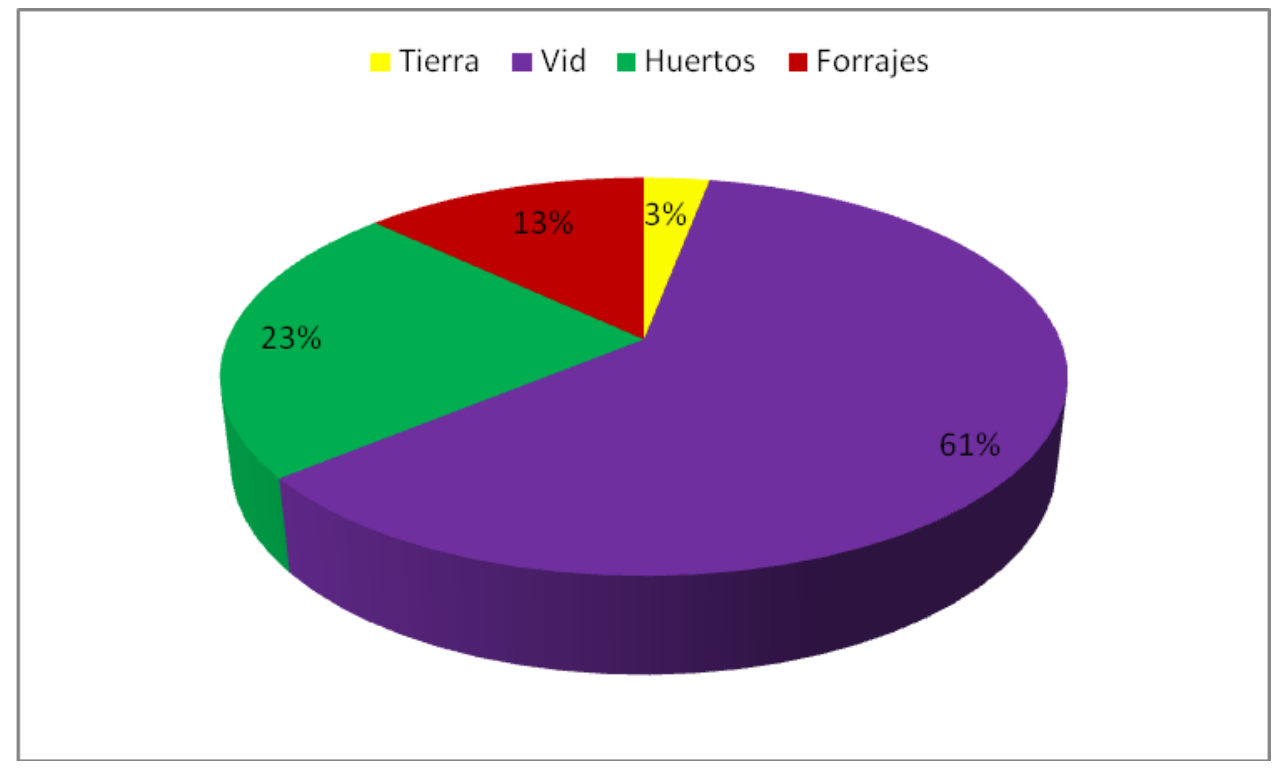

Fig.10. Menciones a Cultivos en la documentación de La Pobla de Benifassà

La partida de los Horts, emplazada en el barranco dels Morts, presenta dos tipos de parcelario y sistemas de riego diferenciados. En primer lugar, la zona norte se caracteriza por parcelas regadas por pozos de cenia, de un tamaño superior y morfología diferenciada a las de la zona sur, emplazadas en el mismo lecho del barranco, siendo así vulnerables al paso del agua en época de lluvias. Además, se ven cruzadas por una cañada, del mismo modo que hay un abrevadero justo al lado de una de las parcelas, la más próxima a la vía ganadera. Estas características, igual que hemos visto anteriormente, nos hacen pensar en ampliaciones.

En cambio, en segundo lugar, podemos observar como la zona sur del barranco, aquí ya canalizado con paredes de piedra seca que reducirían el riesgo por crecidas del torrente, 
presenta unos parcelarios a ambos lados con parcelas de dimensiones reducidas y regadas a partir de distintos sistemas de riego.

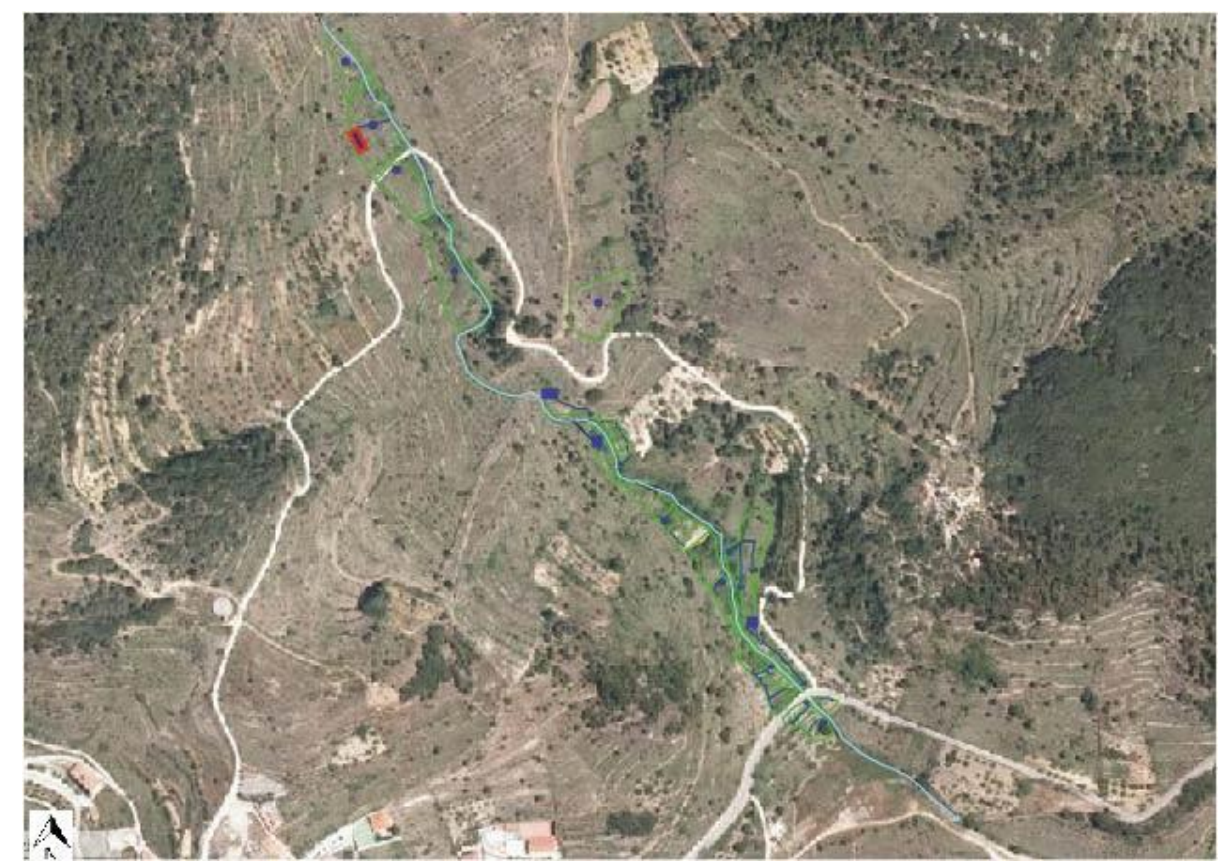

Fig. 11. Parcelario y sistemas de riego de la partida de Els Horts de La Pobla de Benifassà

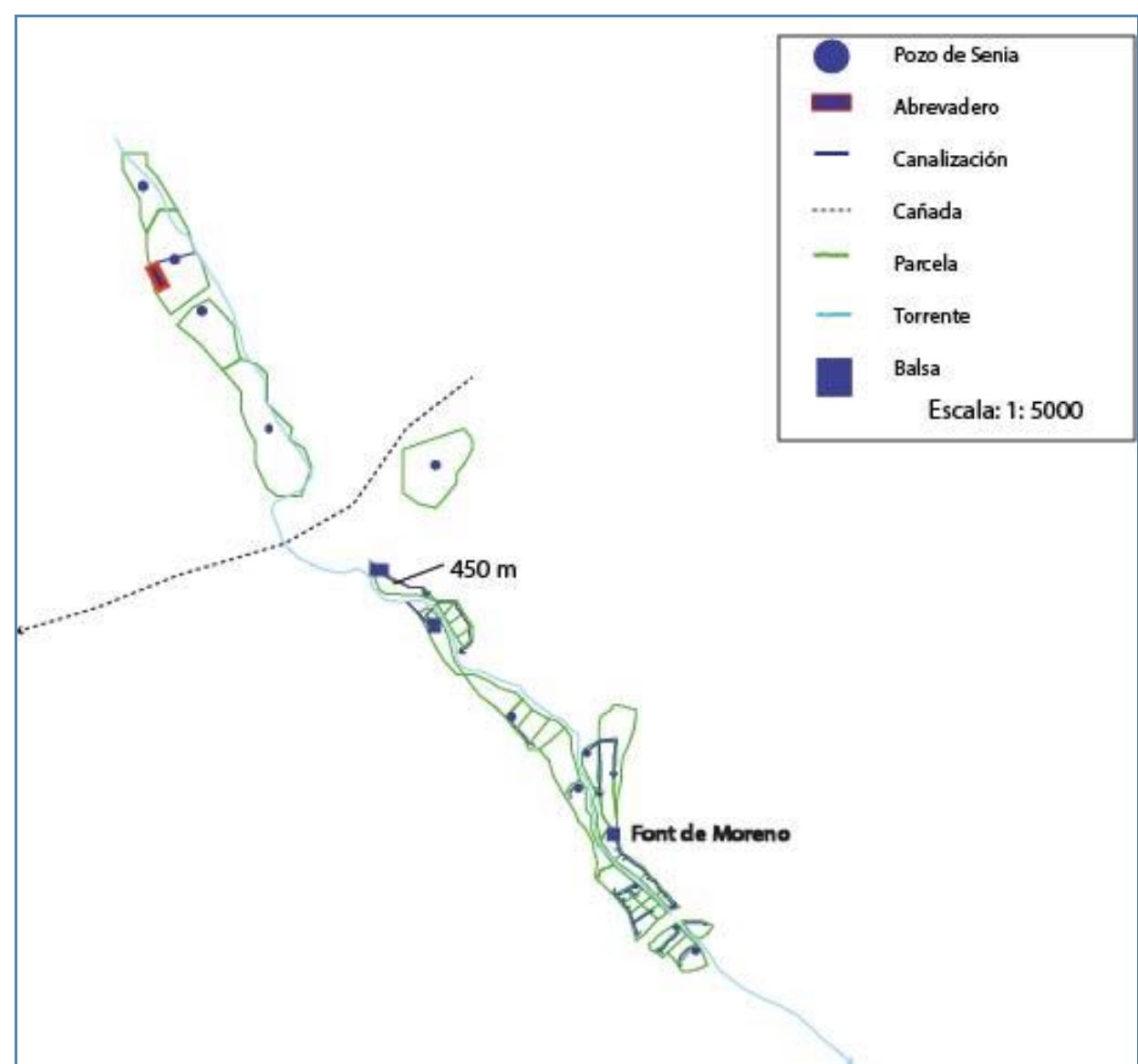

Fig. 12. Parcelario y sistemas de riego de la partida de Els Horts de La Pobla de Benifassà 
Por lo que respecta al margen izquierdo, se riega a partir de cuatro sistemas distintos. En primer lugar, una balsa que se abastece de una fuente natural, regulando su cauce, utilizada para regar una única parcela de $450 \mathrm{~m}^{2}$. En segundo lugar, hay cuatro parcelas que se riegan desde una balsa, situada en el margen derecho del torrente, la que se abastece de agua del torrente mediante un azud. En tercer lugar, encontramos un pozo de cenia que riega diferentes parcelas. Cabe indicar que alguna de éstas presenta una morfología completamente diferente a las contiguas, entendiendo que se trata de una ampliación del sistema. Finalmente, encontramos otra balsa que regula el cauce de la Fuente del Moreno, la que abastece una acequia que riega unas parcelas largas y estrechas.

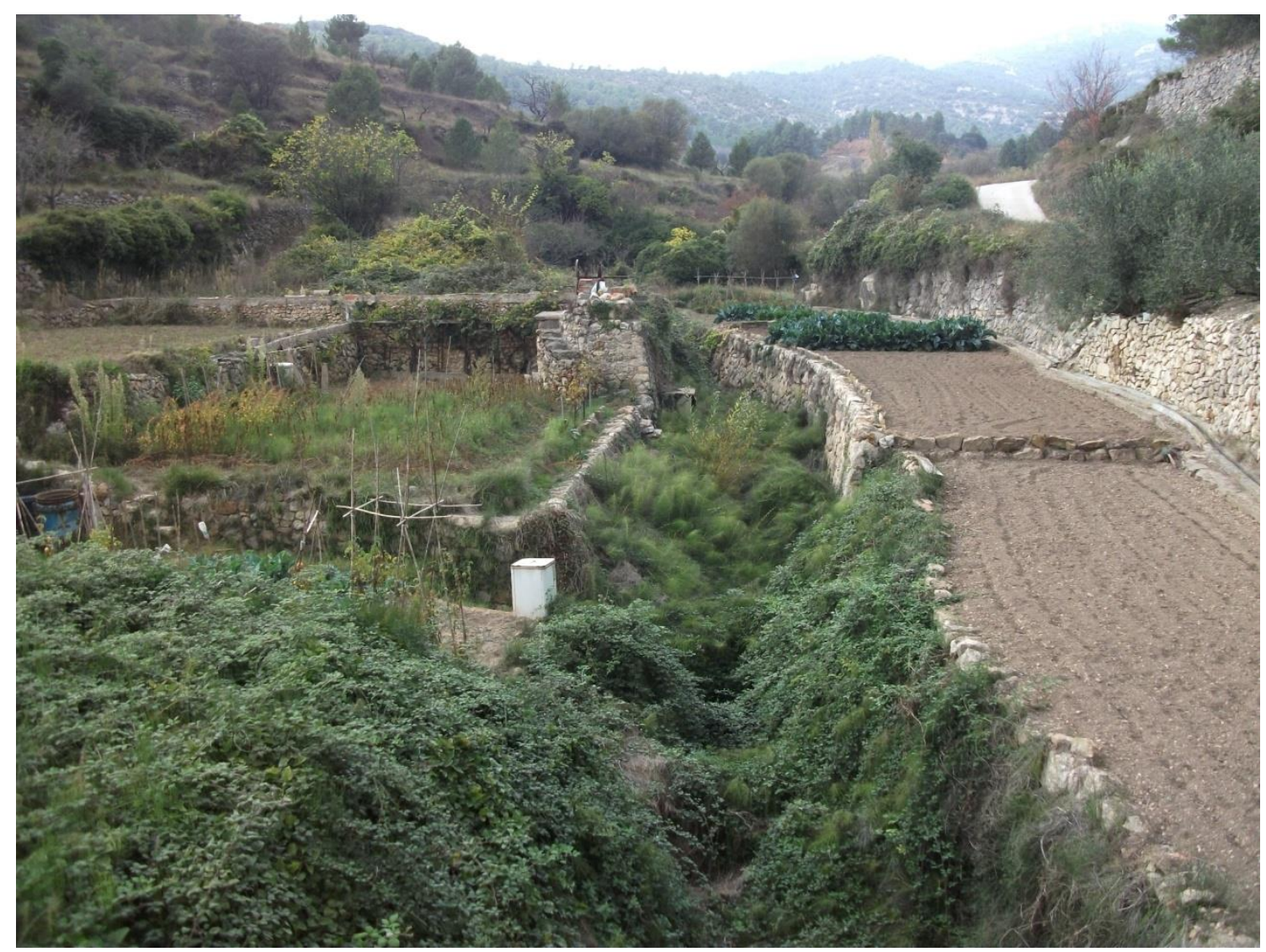

Fig. 13. Foto del parcelario al sur de la Partida dels Horts

En cambio, el margen derecho riega a partir de pozos de cenia situados en el margen del barranco que abastecen parcelas de dimensiones reducidas a excepción de la balsa que ya hemos nombrado. La documentación estudiada sitúa pozos de cenia en la zona sur, tal como atestigua la donación que Pere Moles y su esposa, Martina, hacen a su hijo y nuera de la mitad de su huerto, pero reservándose la mitad de los derechos de agua sobre el pozo ${ }^{32}$.

De modo que, si reducimos las zonas que responden a ampliaciones, resulta un parcelario de posible riego andalusí de 0'6 hectáreas, el que se complementará con un pequeño espacio en la partida de "Davall la vila"

32 AHN, Clero, secular-regular, carpeta 439, n¹ 


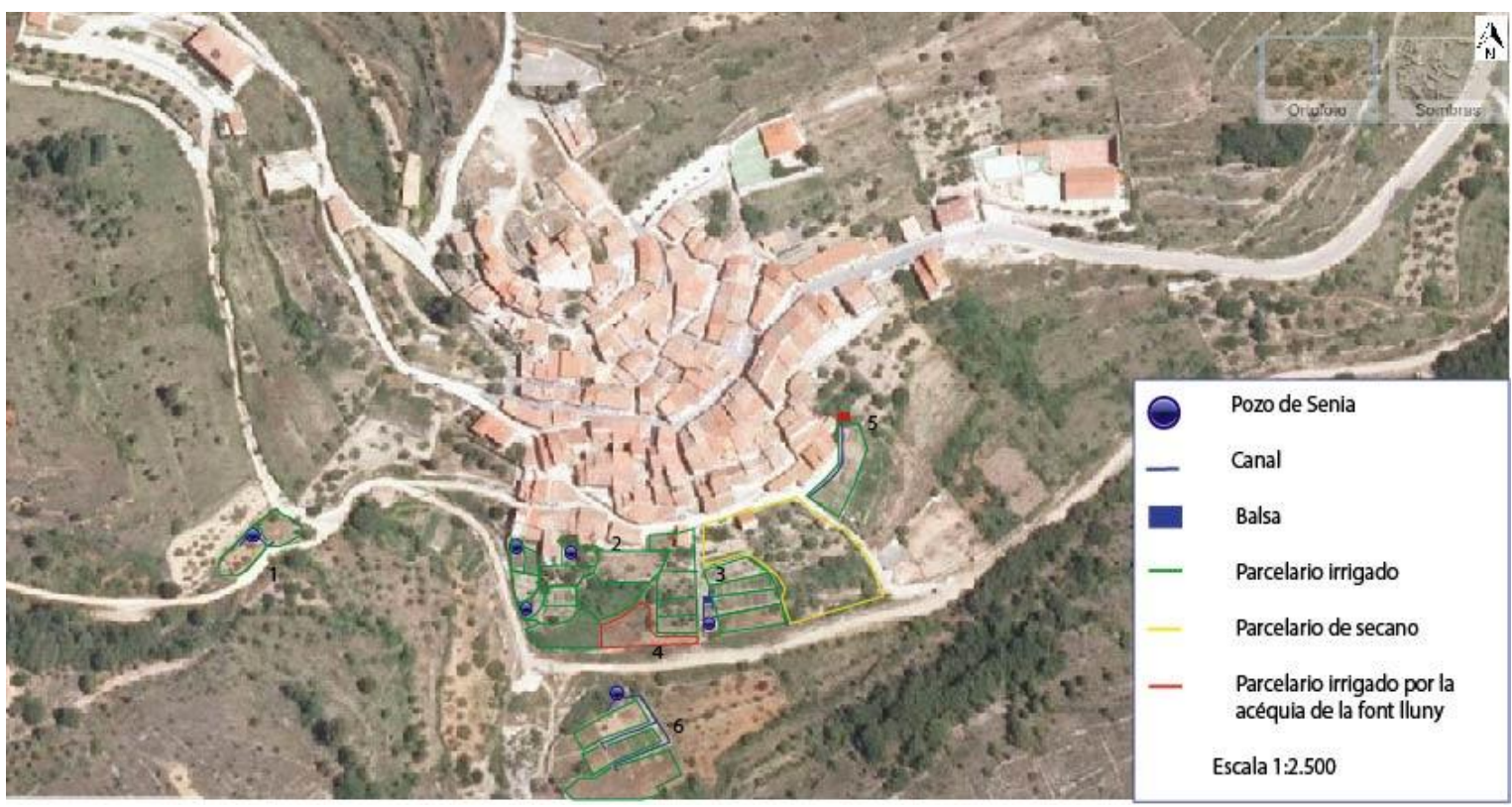

Fig. 14. Parcelario y sistemas de riego de la partida de Davall la vila de La Pobla de Benifassà

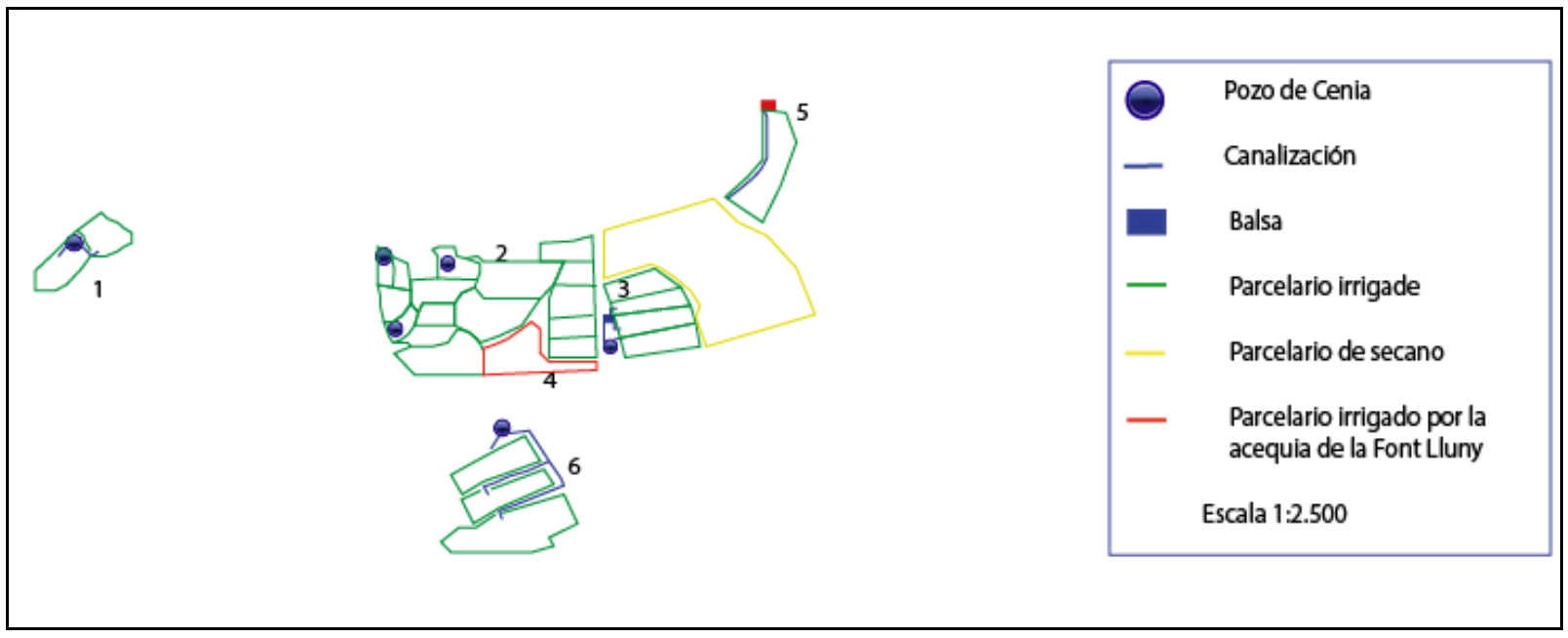

Fig. 15. Parcelario y sistemas de riego de la partida de "Davall la vila"

La zona "Davall la vila" presenta diferentes espacios a analizar, pero cabe advertir que dejaremos de lado los espacios uno y seis del mapa $a^{33}$ porque quedan aislados del sistema. Por un lado, encontramos el espacio cinco regado a partir de una fuente situada en el interior de una casa y de creación muy reciente. En segundo lugar, la zona tres se caracteriza por un parcelario regular regado por un pozo de cenia que abastece una balsa reguladora. En cambio, el parcelario número dos es completamente diferente, ya que es un parcelario irregular i regado por tres pozos de cenia.

${ }^{33}$ Ver Figuras 12 y 13. 


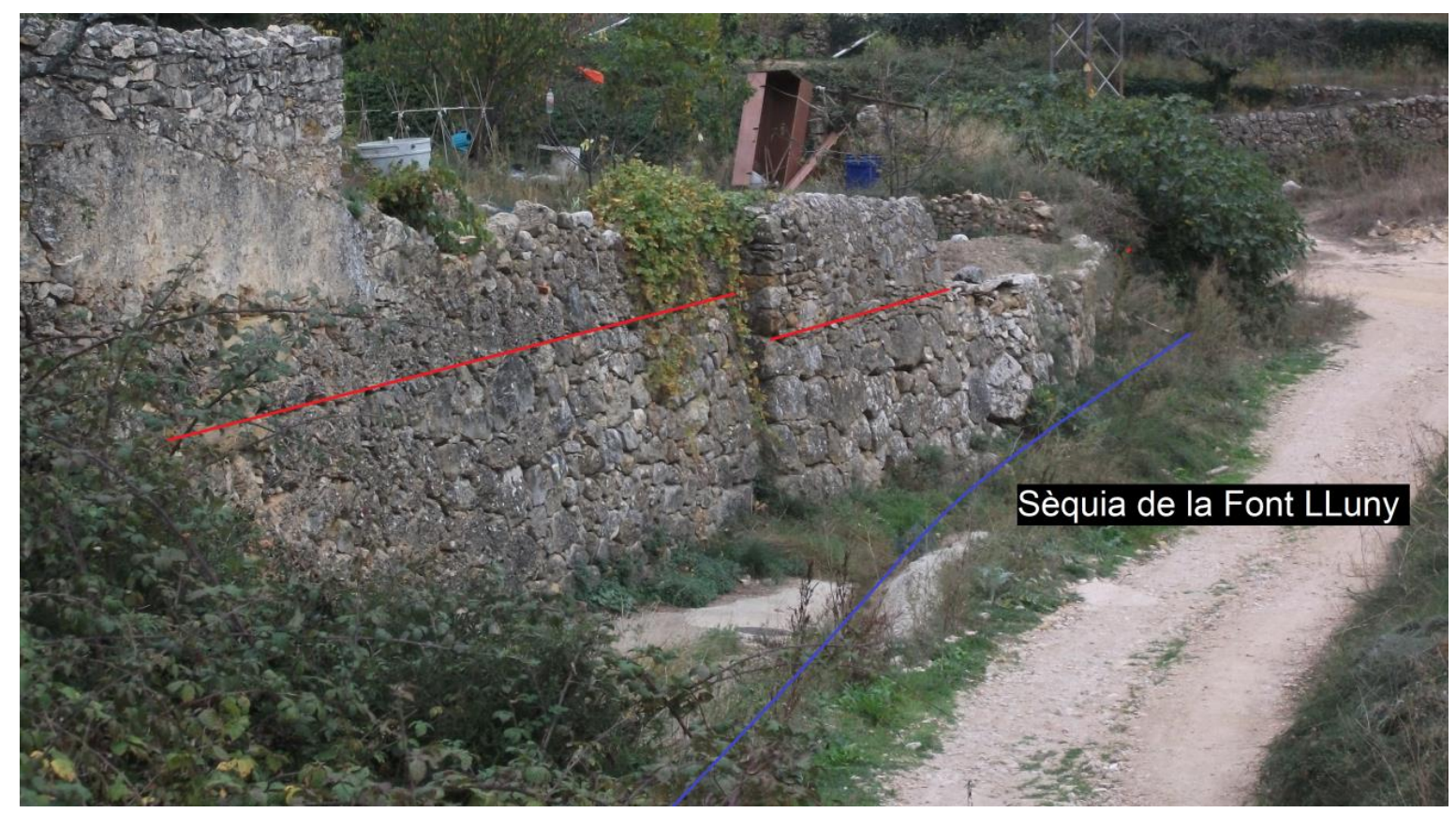

Fig. 16. Pared que separa el parcelario del lecho del río (Foto: M.Pica).

Todo parecería indicar que éste parcelario (2), de 0,12 hectáreas, correspondería al más antiguo de la zona. Está separado del lecho del río por una pared de piedra seca de más de dos metros, con dos fases constructivas, que lo protegería, por un lado de las crecidas del río y por el otro el paso de los rebaños por la cañada que recorre el mismo lecho.

Finalmente, este parcelario se completaría con dos parcelas irrigadas por la acequia de la Font Lluny. Aunque es muy complicado que el agua llegue a ellas, ya que no hay suficiente cabal, así esta sería una ampliación que no garantizaría el riego. Este punto nos ayuda a enlazar con el tercer espacio, irrigado por esta infraestructura.

La acequia de la Font Lluny, nace en la fuente homónima y tiene un recorrido de aproximadamente 900 metros hasta los lavaderos, siendo a la salida de estos donde se bifurca en dos ramales, el que llega a "Davall la vila" y el que riega seis parcelas justo al lado del edificio de los lavaderos. Sin embargo, hay diferentes motivos que nos conducen a pensar en que este parcelario no sería originalmente andalusí.

Por un lado la acequia tiene un recorrido largo, triplicando la media de las estudiadas en la provincia de Castellón (Sitjes, 2006). Por otro lado, el parcelario se sitúa en el margen derecho del lecho del río, pero en una altitud que lo hace vulnerable a inundaciones, así como al paso de una cañada justo por su lado. En este mismo sentido, podemos observar como al principio de la acequia se localiza un abrevadero y al lado de los lavadoress otro, convirtiéndose en un peligro para los cultivos de esta zona. Además, como veremos seguidamente, la granja de Cel Albar dio origen a una villa nueva, por tanto, es posible pensar que estas parcelas se construirían después de los lavaderos, que no tendrían sentido en un lugar sin ocupación andalusí. 


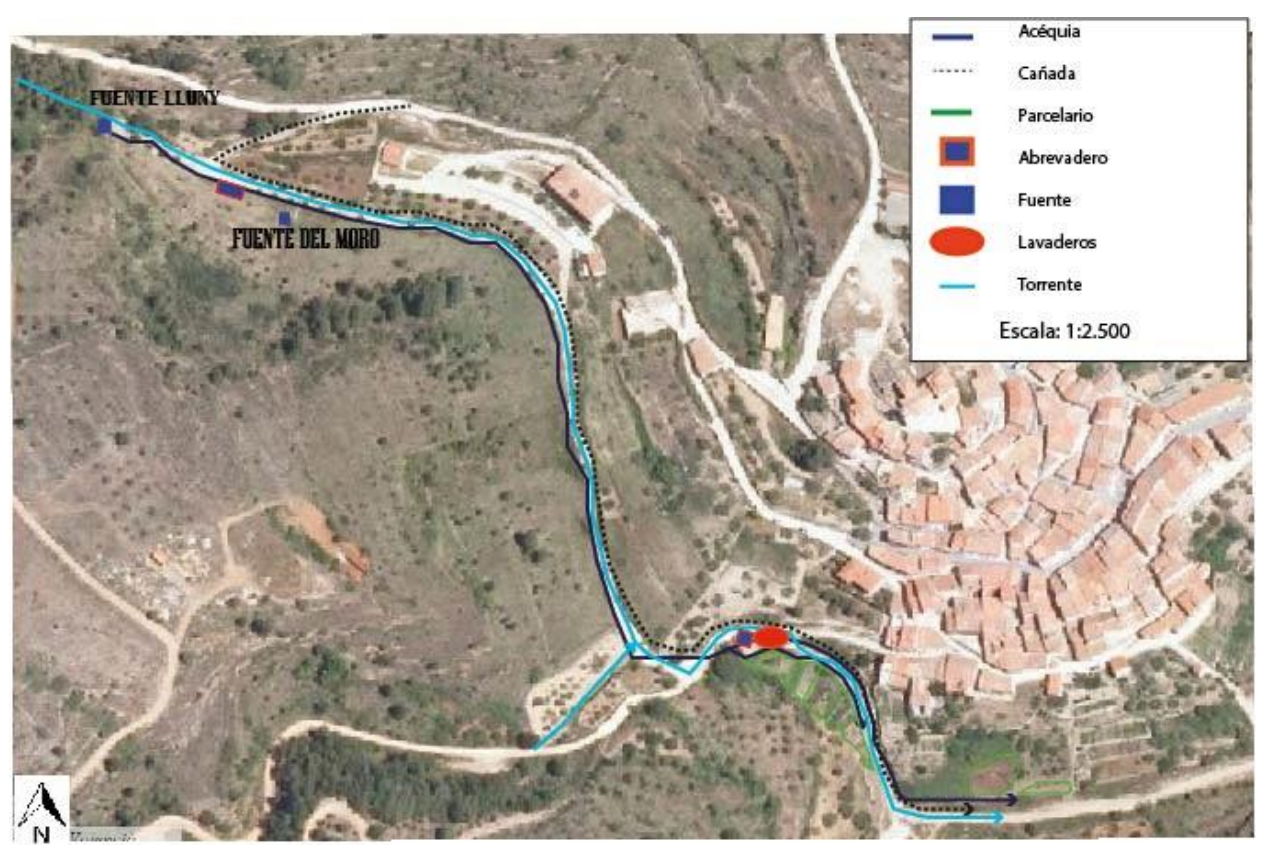

Fig. 17. Parcelario y sistema hidráulico de La Font Lluny

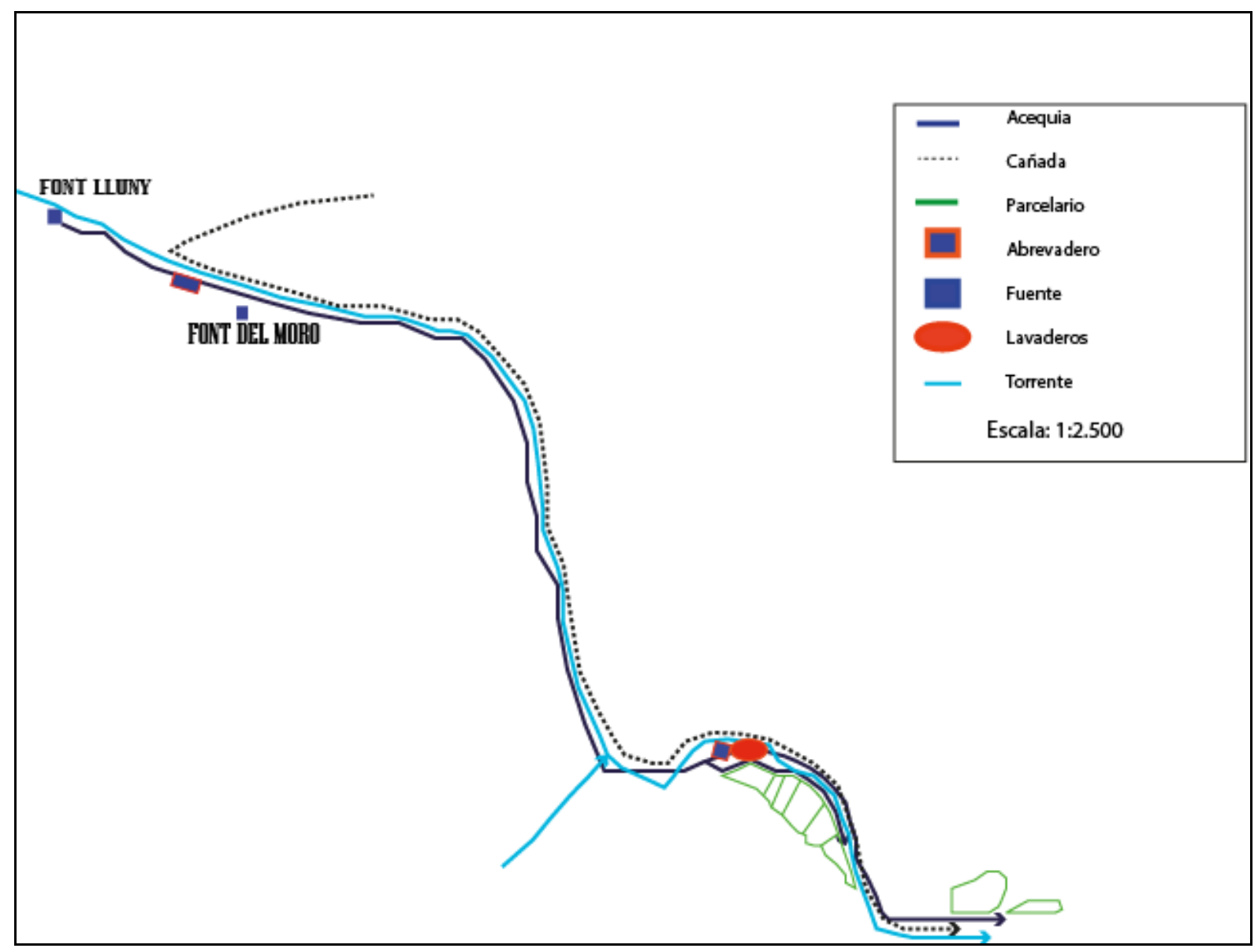

Fig. 18. Parcelario y sistema hidráulico de La Font Lluny 


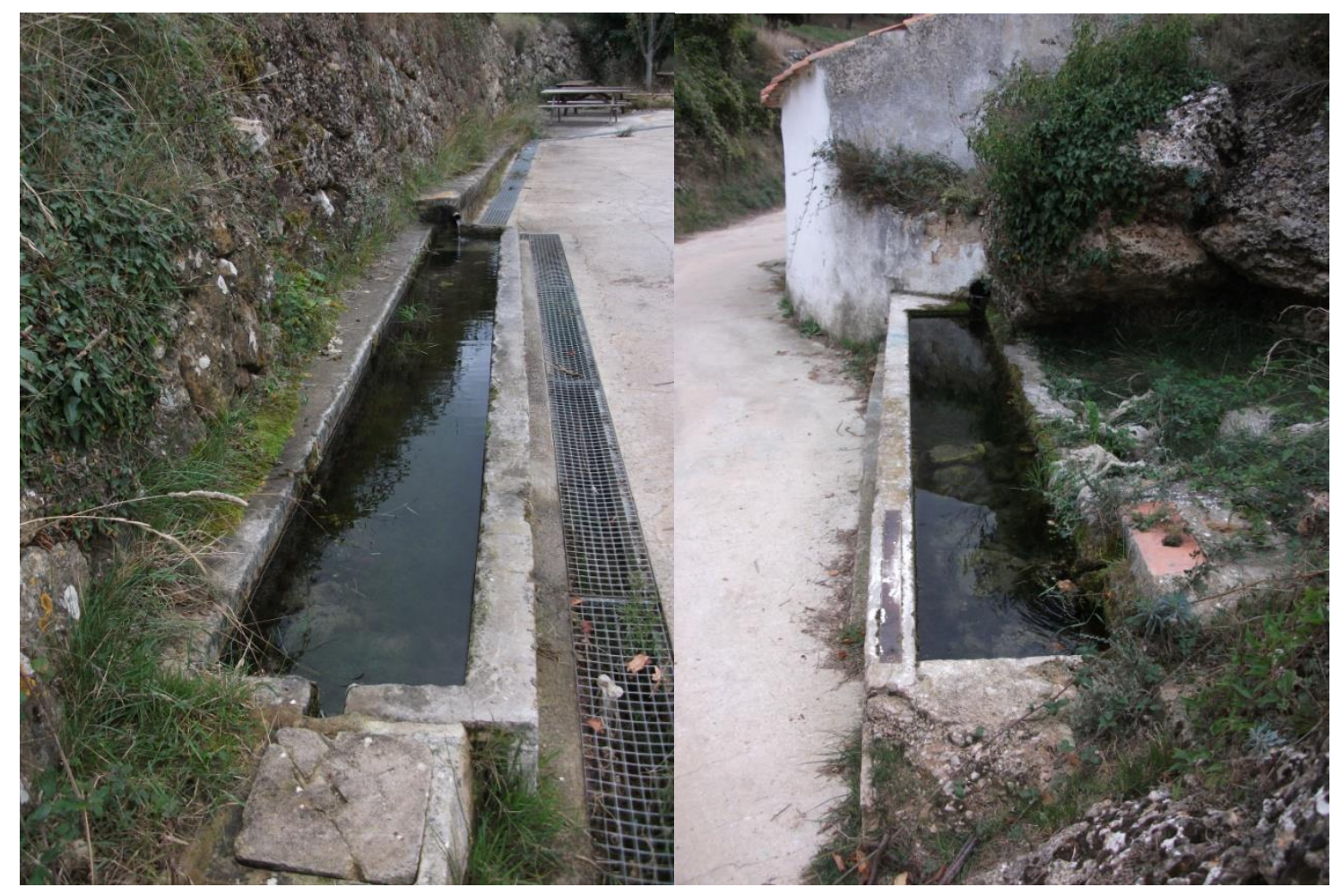

Fig.19. Izq: abrevadero del inicio de la acequia. Derecha: abrevadero al final de la acequia

\section{Los espacios de residencia}

Como hemos observado el análisis de los espacios agrarios determina que nos encontramos delante de tres zonas irrigadas: "Davall la vila" y els Horts para la granja de Cel Albar, y els Horts para Ballestar. Estos espacios son de dimensiones reducidas, de hecho sumando los dos primeros resulta un parcelario inferior a una hectárea y en el tercero la parte posiblemente regada en época andalusí tampoco llega a una hectárea, un hecho habitual en los espacios de riego musulmanes (Sitjes, 2006). Cabe ahora preguntarse por la articulación de estos espacios con la población, o sea, por las áreas de residencia.

La documentación post-conquista aporta poca información sobre la organización poblacional del territorio vinculado al hisn de Benifassà, en todos los documentos aparece la entrega del castillo y su término, no descrito, únicamente especificando que también comprende Bel y Fredes (Virgili, 2001, P.525). Sólo un documento de Jaime I, fechado el 17 de agosto de $1233^{34}$, nos indica la existencia de la alquería de Benifassà. Por lo tanto, tenemos documentado sólo un espacio de residencia con tres espacios agrarios vinculados en el término del hisn de Benifassà.

Podemos determinar que la alquería se localizaba en el emplazamiento actual del municipio de Ballestar, por comparación a La Pobla de Benifassà, ya que ésta última responde claramente a una villa nueva, tal y como se puede observar en el topónimo (Martínez, 2012, pág. 31).

Sin embargo, poco podemos ofrecer del plano urbano de esta alquería, ya que, por un lado no ha llegado a nuestros días ningún documento de alienación de casas, y por otro, no se

34 AHN, Clero, secular-regular, carpeta 418, nº13. 
documenta ninguna actuación arqueológica dentro del recinto urbano. Nos encontramos pues con una problemática habitual cuando las poblaciones cristianas se emplazan encima de los núcleos andalusíes (Torró, 2003; Jiménez, 2004).

En referencia a La Pobla de Benifassà, decíamos que presenta todas las características de una villa nueva, porque, por una parte, el topónimo La Pobla es común entre estas nuevas poblaciones, y por otra, los documentos no dejan lugar a dudas, ya la carta de población establece en todo momento que se trata de una construcción ex novo ${ }^{35}$, y en algunos de los primeros documentos de alienación no se transfieren casas sino "solare domus" construidas.

El acercamiento al pasado andalusí de este asentamiento lo podemos realizar a partir del topónimo de la granja, es decir, Cel Albar, entendiendo que Cel es una deformación escrita del artículo salado del catalán (sa), por tanto el nombre es Sa Albar, o el albar. Albar (Ba') es el único topónimo que se ha conservado para definir espacios de secano en el mundo andalusi ${ }^{37}$, siendo zonas con una tendencia al cultivo no irrigado. En el caso de la documentación conservada para La Pobla, podemos observar como encontramos menos de la mitad de menciones a huertos que en el término de Ballestar. Por otro lado, el topónimo Albar $\left(B a^{\prime}\right)$ se ha puesto en relación con espacios de inclinación a la ganadería (Guichard, 2001, pág. 512), hecho que explicaría la aparición de las menciones a forrajes no documentados en el Ballestar ${ }^{38}$. Otra de las características que se les ha atribuido es la de ocupar zonas de riego esporádico (Guichard, 2001, pág. 512), aunque, como vemos en el territorio que nos atañe, encontramos riegos a partir de fuentes y balsas reguladoras que anularían esta temporalidad.

Por lo que respecta a la organización poblacional de los albares, podemos observar cómo se documentan diferentes casos, tanto en las tierras de Valencia y Murcia como en Mallorca, como rahales dependientes de otras alquerías (Guichard, 2001, págs. 511-14), unos barrios que no tienen necesidad de ser poblados, sino únicamente productivos, o bien que pueden tener una entidad muy pequeña (Kirchner, 2009, págs. 160-63), motivos por los que los cristianos en conquistar Benifassà no documentaron el rabal en cuestión, como si lo hicieron en otros emplazamientos con la expresión "alquería cum suo rafalo" (Kirchner, 2009, pág. 161). Por tanto, nos encontramos delante de un espacio agrario dependiente de la alquería de Benifassà, actualmente Ballestar, en el que el primer asentamiento humano se produciría con la llegada del monasterio y la implantación de la granja, duplicando así los núcleos urbanos para el mismo espacio irrigado. Cabe decir que este espacio irrigado, situado en el albar, posiblemente se fundó des de un principio para evitar riesgos productivos (Retamero, 2006) y no para cubrir una eventual crecida demográfica (Boserup, 1956), aunque necesitaríamos dataciones absolutas para poder determinarlo.

Siguiendo con la implantación de la villa nueva, el cambio es aún superior si entramos en el número de pobladores que los abades establecen en cada uno de los municipios, ya que mientras Ballestar será dado a veinte pobladores (Guinot, 1991, p. 187), o sea familias, La Pobla será habitada por diez familias más (Guinot, 1991, p. 124), las cuales dispondrán de un espacio irrigado inferior o tendrán, seguramente, más necesidad de ampliarlo.

\footnotetext{
${ }^{35}$ La carta de población (Guinot, 1991, p. 124) establece en todo momento que se trata de una construcción ex novo.

36 AHN, Clero, secular-regular, carpeta 424, no8, 10. AHN, Clero, secular-regular, carpeta 426, n¹5

37 Afirmación sostenida por diferentes autores (Corriente, 2010) (Torró, 2006, pág. 117) (Guichard, 2001, pág. 512).

${ }^{38}$ Ver gráficos 1 y 2.
} 
Sin embargo, aunque el número de pobladores sea superior, no implica que las dependencias con el Ballestar, primero granja principal y después villa, sean eliminadas completamente, sino que se detecta cómo el monasterio establece unas legislaciones que mantienen la vinculación de la nueva villa hacia el Ballestar. Por ejemplo, la vendimia se realizará primero en el término de Ballestar y después en La Pobla ${ }^{39}$. Además, los habitantes de La Pobla podrán construir una herrería (Guinot, 1991, p. 124) ${ }^{40}$, aunque para que el monasterio pueda mantener el control de la tasa sobre el afilado de arados tendrán que ir a afilar a la fábrica de Ballestar ${ }^{41}$.

La presencia de una fábrica en la granja de Ballestar, así como la construcción de otra en La Pobla, núcleos separados por menos de dos quilómetros, y la localización de diferentes minas de hierro en la zona, nos conduce a preguntarnos por la explotación de las minas de hierro de Benifassà en época andalusí, ya que sabemos de numerosas granjas que se establecen en emplazamientos con orientaciones similares ${ }^{42}$.

La minería está bien documentada justo después del control del territorio. Ya el rey Jaime I entrega todas las minas del territorio al monasterio ${ }^{43}$, a excepción de las de oro y plata sobre las que mantendrá el control él mismo ${ }^{44}$. Ésto nos conduce a seguir indagando en la extracción minera andalusí en las numerosas minas de hierro, sobre todo en los términos de Ballestar, ya que encontramos una de ellas, por ejemplo, en los pies del cerro de La Santa Escolástica, donde se emplaza el hisn de Benifassà. Además, el territorio no es únicamente rico en hierro, sino que también se constata la presencia y extracción de Vitriolo y caparrosa ${ }^{45}$, unos minerales ya conocidos y explotados en época andalusí (Menasanch, 2000). Aun con todo, sólo la continuación de los trabajos y el estudio sistemático sobre este territorio permitirán aportar más luz a la posible vinculación minera.

\section{Conclusiones}

La conquista del territorio de Benifassà, con el consecuente cambio de modelo social y poblacional, se vio marcada por las disputas entre los diferentes señores feudales que durante sucesivos reinados recibieron la donación del territorio, fruto de su enclave caracterizado por ser durante más de ochenta años la frontera entre al-Ándalus y la Corona de Aragón.

Las distintas disputas originadas con el repartimiento posterior a la conquista conllevaron la ruptura de la estructura castral andalusí, pasando tras la conquista a la unificación en un solo término del territorio asociado a dos husun, Benifassà y Castell de Cabres, con la única excepción del término de Herbeset que pasó de estar vinculado a Castell de Cabres a formar parte del territorio de Morella. Por otro lado, el monasterio de Santa María de

\footnotetext{
39 ACT, Índex de l'Arxiu del monestir de Benifassà, f.81. Podríamos pensar que el orden de vendimia se organizara por razón de altitud. La diferencia de altitud entre los dos términos es mínima, hecho que anula esa posibilidad.

${ }^{40}$ Los pobladores ejecutaran su derecho tal como se observa en los límites de la casa del horno de La Pobla. (AHN, Clero, secular-regular, carpeta 424, n'2)

41 Guinot, 1991, p. 124

${ }^{42}$ Ver cita 16.

43 En este sentido, tal y como indica Cressier no podemos concluir la práctica minera en épocas anteriores, aunque si plantear su existencia (1998).

${ }^{44} \mathrm{ACT}$, cajón Benifassà, no 4

${ }^{45} \mathrm{La}$ documentación de estas extracciones las conocemos por el trabajo realizado por José Cavanilles en el siglo XVIII (Cavanilles, 1795, págs. 2-3).
} 
Benifassà tuvo que optar por organizar parte del territorio a partir de granjas cistercienses para evitar el escape de ingresos que supuso la adquisición por parte de la Catedral de Tortosa de ventajas sobre su territorio. En este sentido, las granjas de Cel Albar y el Ballestar se implantaron en territorios ya explotados, como es habitual (Bond, 2003), concretamente, en la alquería de Benifassá en el enclave dónde hoy encontramos el Ballestar, y en el rahal vinculado a ella, en el término de la granja de Cel Albar, hoy La Pobla de Benifassà.

Así, tras la conquista en el término de la alquería, formado por espacio de residencia, espacio agrario y un rahal productivo, no habitado y con clara inclinación al secano (Corriente, 2010), aunque con espacios irrigados de pequeño tamaño, se implantaron dos granjas cistercienses, las que, años más tarde, con la entrega de cartas puebla por parte del monasterio, resultaron villas, la primera de ellas de nueva planta y con un topónimo muy esclarecedor, La Pobla, sin pasado poblacional andalusí, situada en el albar. La segunda, el Ballestar, se emplazó encima de la antigua alquería.

Por lo que respecta a los espacios irrigados menores situados en el albar, posiblemente se diseñaron de un inicio para evitar riesgos (Retamero, 2006, pág. 306) y no con posterioridad para solucionar eventuales crecidas demográficas, aunque solo la obtención de dataciones absolutas permitiría esclarecer la cuestión en este territorio.

Además, el proceso de colonización del territorio produjo un hondo cambio de tamaño poblacional, ya que el rahal, no habitado en época andalusí, originó una villa con más pobladores que la villa del Ballestar, situada encima de la antigua alquería, contando con un espacio irrigado inferior. Además, aunque La Pobla de Benifassà tuviera más pobladores que el Ballestar siguió vinculada, en ciertos aspectosm al municipio vecino, vinculación dirigida des del monasterio.

Por último, no podemos concluir sin hacer referencia a las perspectivas de investigación que nos ofrece el territorio de Benifassà en dos sentidos. En primer lugar, creemos que sería interesante seguir en el estudio de la minería, ya que la documentación de minas en el momento de la conquista y la localización de una fábrica en la granja nos hace pensar en la continuidad de ésta des de época andalusí (Cressier, 1998). Además, sabemos que las granjas cistercienses se emplazan en algunos lugares que tienen esta inclinación productiva, y también conocemos la presencia en el territorio de minerales conocidos y utilizados por los musulmanes, como el hierro o la caparrosa. En segundo lugar, sería conveniente estudiar la ganadería porque los indicios nos conducen a pensar en un mantenimiento de las cañadas andalusíes por parte del monasterio, así como la posibilidad documental de definir los espacios ganaderos de cada población (Cara, 2009) y analizar la interacción entre ellos, la agricultura y la población humana.

\section{Referencias}

Altisent, A. (1974). Historia de Poblet. Abadia de Poblet.

Arroyo, F. (1973). Blasco de alagón y el principio de la reconquista valenciana. Estudios de la Edad Media de la Corona de Aragón , 71-99.

Barceló, M. (1988). La arqueología extensiva y el estudio de la creación del espacio rural. En M. Barceló, Arqueología medieval. En las afueras del medievalismo (págs. 195-274). Barcelona: Crítica. 
Barceló, M et alii (1996) El agua que no duerme. Fundamentos de la arqueología bidráulica andalusí (págs. 91-118). Granada: El legado andalusí/ Sierra Nevada 95.

Barceló, M. (1999). Saber lo que es un espacio hidráulico y lo que no es. En A. Bazzana, CASTRUM 5. Archéologie des espaces agraires méditerranéens au Moyen Âge. (págs. 277-285). Madrid, Murcia, Roma: Casa de Velázquez, Ayuntamiento de Murcia, École française de Rome.

Barceló, M; Retamero, F. (2005). Els barrancs tancats. L'ordre pagès al sud de Menorca en època andalusina (X-XIII). Maó: IEB.

Batet, C. (2006). L'aigua conquerida. Valencia: PUV.

Belenguer, E. (2007). Jaume I i el seu regnat. Lleida: Pagès Editors.

Bolós, J. (2005). La implantació del císter al territori: La formació del patrimoni i la transformació del paisatge. Actes del primer curs-simposi sobre monaquisme cistercenc, (págs. 35-68). Santes Creus .

Bond, J. (2003). Monastic Landscapes. Tempus.

Cara, L. (2009). Huella de pastores: observando los paisajes ganaderos de los "extremos" granadinos. En A. Malpica, Análisis de los paisajes históricos/ De al-Andalus a la sociedad feudal (págs. 169-202). Granada: Kadmos.

Carreras, A. (1992). El monestir de Santes Creus 1150-1200 (Formació del domini patrimonial 1). Valls: I.E.V.

Cavanilles, A. (1795). Observaciones sobre la Historia Natural, Geografía, Agricultura, población y frutos del reyno de Valencia. Madrid.

Chauvin, B. (1983). De la villa carolingienne a la grange cistercienne. Le cas de la terre de Glénon (Arbois, Jura). Du milieu du X a la fin de XIV siecle. En Janssen, \& Lohrmann, Villa, curtis, grangia: Landwirtschaft zwischen Loire und Rhein von der Romerzeit zum Hochmittelalter (págs. 166-183). Munich.

Corriente, F. (2010). Huellas Lingüísticas de secanos y regadíos en el occidente islámico . En F. Sabaté, Arqueologia Medieval. Els espais de secà (IV) (págs. 19-30). LLeida: Pagès Editors.

Cressier, P. (1998). Observaciones sobre fortificación y minería en la Almería islámica. En A. Malpica, Castillos y territorio en al-Andalus (págs. 470-496). Granada.

Dagorn, R. (1975). Le document almohade de Poblet. Les Cabiers de Tunisie, XXIII , 69-90.

Domènech, V. (1984). La querella entre el monasterio de Santa María de Benifazá y el monasterio de Santa María de Scarp . Boletín de la Sociedad Castellonense de Cultura, 60 , 189211.

Eritja, X. (2000). Dominicum comitis: Estructuració feudal de l'horta urbana de Rufea (Lleida) durant la segtona meitat del segle XII. En E. Vicedo, Terra, aigua, societat $i$ conflicte a la Catalunya Occidental (págs. 25-46). Lleida: Pagès.

Esquilache, F. (2011). L'evolució del paisatge agrari andalusí i feudal de les grans hortes fluvials. Les sèquies de Quart i del Comuner d'Aldaia a l'horta de València. Recerques 62 , 5 36.

Font i Rius, J. (1969). Cartas de población y franquicia de Cataluña. Madrid: CSIC.

Garcia-Oliver, F. (1998). Cistercencs al País V alencià. El Monestir de Valldigna (1295-1530). Valencia: Tres i Quatre. 
Guichard, P. (2001). Al-Andalus frente a la conquista cristiana. Valencia: PUV.

Guinot, E. (1991). Cartes de Població Medievals Valencianes. Valencia: Generalitat Valenciana.

Guinot, E. (2002). El riu de la Sénia: sistemes de reg i molins medievals. Acta bistorica et archaeologica mediaevalia , 103-121.

Guinot, E. (1995). Els limits del regne. Valencia: Alfons el Magnànim.

Guinot, E. (2005). Usos i conflictes de l'aigua. Afers, 51 , 265-270.

Hodges, R. (1991). W all-to-wall History. The story of Roystone Grange. Londres: Ruckworth.

Jiménez, J. (2004). Algunas reflexiones sobre la gestión del patrimonio arqueológico valenciano en las dos últimas décadas. Saitabi. Revista de la facultat de Geografia i Història, 5. , $37-61$

Kirchner, H. (2012). Hidráulica campesina anterior a la generalización del dominio feudal. Casos en Cataluña. En J. T. E. Guinot, Hidráulica agraria y sociedad feudal (págs. 21-50). València: PUV.

Kirchner, H. (1997). La construcció de l'espai pagès a Mayûrqa, les valls de Bunyola, Orient, Coanegra i Alaró. Palma: UIB.

Kirchner, H. (2009). Original design, tribal management and modifications in medieval hydraulic systems in the Balearic Islands (Spain). World Archaeology, 41 , 150-168.

Kirchner,H; Virgili, A; Antolín, F. (2014). Un espacio de cultivo urbano en al-Andalus: Madina Turtusa (Tortosa) antes de 1148. Historia agraria, 62 , 11-45.

Martínez, I. (2012). Eñs Origens de la indústria rural. L'artesanat a l'Alzira i la Ribera en els segles XIII-XV. Valencia: PUV.

Mateu i Llopis, F. (1969). Establiments de la vila de El Boixar. Catellón de la Plana: Sociedad Castellonense de Cultura.

Menasanch, M. (2000). Una aproximación a la minería y la metalurgia andalusí en la depresión de Vera (Almería). Arqueología y territorio medieval, $n^{\circ} 7,59-80$.

Pallares, M.C; Portela, E. (2000). El complejo minerometatúrgico de la granja cisterciense de Constantín. Bases para el desarrollo de una investigación en arqueología medieval. Arqueología y territorio Medieval,7 , 81-91.

Retamero, F. (2006). Lo que el tamaño importa. Cuándo y por qué se modificaron los antiguos sistemas hidráulicos andalusíes. Arqueología Espacial 26 , 293-310.

Rodríguez, E. (2005). San Tirso, en Villarrín de Campos (Zamora): una granja cisterciense del monasterio de Sobrado de loa Monjes (La Coruña), junto al coto del monasterio de Moreruela (Zamora). Brigecio, 15 , 65-70.

Sitjes, E. (2006). Inventario y tipología de sistemas hidráulicos de Al-Andalus. Arqueologia Espacial, 26, 263-292.

Torró, J. (2003). Arqueologia de la conquesta. Registre material, substitució de poblacions i transformació de l'espai rural valencià (segles XIII-XIV). En M. e. Barceló, El feudalisme, comptat $i$ debatut. Formació $i$ expansió del feudalisme català (págs. 153-200). València: PUV.

Torró, J. (2006). El naixement d'una colònia. Dominació i resistència a la frontera valenciana (12381276). València: PUV. 
Trillo, C. (1999). El paisage vegetal en la Granada Islámica y sus transformaciones tras la conquista castellana. Historia agraria, 17: 131-152.

Virgili, A. (2001). Diplomatari de la Catedral de Tortosa (1193-1212). Barcelona: Fundació Noguera.

Virgili, A. (2005). L'economia monacal, treball i renda feudal en els monestirs cistercencs. Actes del primer curs-simposi sobre monaquisme cistercenc, (pp. 75-97). Santes Creus. 